\title{
Native to Designed: Microbial $\alpha$-Amylases for Industrial Applications
}

\author{
Si Jie Lim ${ }^{1,2}$, Siti Nurbaya Oslan ${ }^{\text {Corresp. 1, 2,3 }}$ \\ ${ }^{1}$ Enzyme Technology Laboratory, Institute of Bioscience., Universiti Putra Malaysia, Serdang, Selangor, Malaysia \\ Enzyme and Microbial Technology (EMTech) Research Centre, Universiti Putra Malaysia, Serdang, Selangor, Malaysia \\ 3 Department of Biochemistry, Faculty of Biotechnology and Biomolecular Sciences, Universiti Putra Malaysia, Serdang, Selangor, Malaysia \\ Corresponding Author: Siti Nurbaya Oslan \\ Email address: snurbayaoslan@upm.edu.my
}

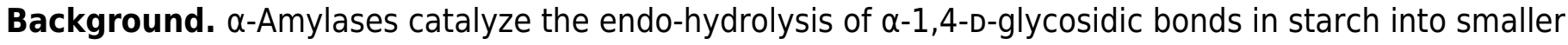
moieties. While industrial processes are usually performed at harsh conditions, $\alpha$-amylases from mainly the bacteria, fungi and yeasts are preferred for their stabilities (thermal, pH and oxidative) and specificities (substrate and product). Microbial $\alpha$-amylases can be purified and characterized for industrial applications. While exploring novel enzymes with these properties in the nature is time-costly, the advancements in protein engineering techniques including rational design, directed evolution and others have privileged their modifications to exhibit industrially ideal traits. However, the commentary on the strategies and preferably mutated residues are lacking, hindering the design of new mutants especially for enhanced substrate specificity and oxidative stability. Thus, our review ensures wider accessibility of the previously reported experimental findings to facilitate the future engineering work.

Survey methodology and objectives. A traditional review approach was taken to focus on the engineering of microbial $\alpha$-amylases to enhance industrially favoured characteristics. The action mechanisms of $\alpha$ - and $\beta$-amylases were compared to avoid any bias in the research background. This review aimed to discuss the advances in modifying microbial $\alpha$-amylases via protein engineering to achieve longer half-life in high temperature, improved resistance (acidic, alkaline and oxidative) and enhanced specificities (substrate and product). Captivating results were discussed in depth, including the extended half-life at $100{ }^{\circ} \mathrm{C}, \mathrm{pH} 3.5$ and $10,1.8 \mathrm{M}$ hydrogen peroxide as well as enhanced substrate $(65.3 \%)$ and product (42.4\%) specificities. These shed light to the future microbial $\alpha$-amylase engineering in achieving paramount biochemical traits ameliorations to apt in the industries.

Conclusions. Microbial $\alpha$-amylases can be tailored for specific industrial applications through protein engineering (rational design and directed evolution). While the critical mutation points are dependent on respective enzymes, formation of disulfide bridge between cysteine residues after mutations is crucial for elevated thermostability. Amino acids conversion to basic residues was reported for enhanced acidic resistance while hydrophobic interaction resulted from mutated hydrophobic residues in carbohydratebinding module or surface-binding sites is pivotal for improved substrate specificity. Substitution of oxidation-prone methionine residues with non-polar residues increases the enzyme oxidative stability. Hence, this review provides conceptual advances for the future microbial $\alpha$-amylases designs to exhibit industrially significant characteristics. However, more attention is needed to enhance substrate specificity and oxidative stability since they are least reported. 
1 Native to Designed: Microbial $\alpha$-Amylases for 2 Industrial Applications

3

4

5

6

7

8

\section{9}

10

11

12

13

14

15

16

17

18

19

20

21

22

23

24

25

26

27

28

29

30

31

32

33

34

35

36

37

38

39

Si Jie Lim ${ }^{1,2}$, Siti Nurbaya Oslan ${ }^{1,2,3}$

${ }^{1}$ Enzyme Technology Laboratory, Institute of Bioscience, Universiti Putra Malaysia, 43400 UPM Serdang, Selangor, Malaysia

${ }^{2}$ Enzyme and Microbial Technology (EMTech) Research Centre, Faculty of Biotechnology and Biomolecular Sciences, Universiti Putra Malaysia, 43400 UPM Serdang, Selangor, Malaysia.

${ }^{3}$ Department of Biochemistry, Faculty of Biotechnology and Biomolecular Sciences, Universiti Putra Malaysia, 43400 UPM Serdang, Selangor, Malaysia.

Corresponding Author:

Siti Nurbaya Oslan $1,2,3$

Universiti Putra Malaysia, 43400 UPM Serdang, Selangor, Malaysia

Email address: snurbayaoslan@upm.edu.my

\section{Abstract}

Background. $\alpha$-Amylases catalyze the endo-hydrolysis of $\alpha-1,4-\mathrm{D}-\mathrm{glycosidic}$ bonds in starch into smaller moieties. While industrial processes are usually performed at harsh conditions, $\alpha$ amylases from mainly the bacteria, fungi and yeasts are preferred for their stabilities (thermal, $\mathrm{pH}$ and oxidative) and specificities (substrate and product). Microbial $\alpha$-amylases can be purified and characterized for industrial applications. While exploring novel enzymes with these properties in the nature is time-costly, the advancements in protein engineering techniques including rational design, directed evolution and others have privileged their modifications to exhibit industrially ideal traits. However, the commentary on the strategies and preferably mutated residues are lacking, hindering the design of new mutants especially for enhanced substrate specificity and oxidative stability. Thus, our review ensures wider accessibility of the previously reported experimental findings to facilitate the future engineering work.

Survey methodology and objectives. A traditional review approach was taken to focus on the engineering of microbial $\alpha$-amylases to enhance industrially favoured characteristics. The action mechanisms of $\alpha$ - and $\beta$-amylases were compared to avoid any bias in the research background. This review aimed to discuss the advances in modifying microbial $\alpha$-amylases via protein engineering to achieve longer half-life in high temperature, improved resistance (acidic, alkaline and oxidative) and enhanced specificities (substrate and product). Captivating results were discussed in depth, including the extended half-life at $100^{\circ} \mathrm{C}, \mathrm{pH} 3.5$ and $10,1.8 \mathrm{M}$ hydrogen peroxide as well as enhanced substrate (65.3\%) and product (42.4\%) specificities. These shed light to the future microbial $\alpha$-amylase engineering in achieving paramount biochemical traits ameliorations to apt in the industries. 
40 Conclusions. Microbial $\alpha$-amylases can be tailored for specific industrial applications through 41 protein engineering (rational design and directed evolution). While the critical mutation points 42 are dependent on respective enzymes, formation of disulfide bridge between cysteine residues 43 after mutations is crucial for elevated thermostability. Amino acids conversion to basic residues 44 was reported for enhanced acidic resistance while hydrophobic interaction resulted from mutated 45 hydrophobic residues in carbohydrate-binding module or surface-binding sites is pivotal for 46 improved substrate specificity. Substitution of oxidation-prone methionine residues with non47 polar residues increases the enzyme oxidative stability. Hence, this review provides conceptual 48 advances for the future microbial $\alpha$-amylases designs to exhibit industrially significant 49 characteristics. However, more attention is needed to enhance substrate specificity and oxidative 50 51

\section{Introduction}

53 In recent years, protein engineering has been equipped as a powerful tool to elucidate the structural functions of proteins (enzymes) and modify them for enhanced properties to solve various global issues. In treating multidrug-resistant Staphylococcus aureus (MRSA) infections through lysis, the fusion of peptidoglycan hydrolase (PGHase) with an albumin binding domain (ABD) had rendered the mutant (enzymbiotic) to exhibit an elevated half-life in human blood serum, strengthening its therapeutics potential (Sobieraj et al., 2020). While $\beta$-glucosidase had been utilized to reduce the fossil-based fuels dependency through lignocellulosic biomass conversion into second-generation biofuels (Contreras et al., 2020), its engineering had improved its glucose tolerance (end-product inhibition) besides enhancing its half-life at intermediate temperature $\left(50^{\circ} \mathrm{C}\right)(\mathrm{Cao}$ et al., 2020).

Despite the medical field and biofuel industry which are beneficial from the engineering of PGHase and $\beta$-glucosidase, respectively, $\alpha$-amylases (E.C. 3.2.1.1) which catalyze the endohydrolysis of $\alpha-1,4$-glycosidic linkages in starch to produce small carbohydrate moieties have been applied in various industries encompassing food and fruits processing, textile and paper, detergent, biofuel and animal feeds industries. Being a carbohydrate-active enzyme, $\alpha$ amylase sequences have also been deposited and classified in the Carbohydrate-Active Enzyme (CAZy) database (http://www.cazy.org/) (Lombard et al., 2014). Out of 170 glycoside hydrolase (GH) families, the biggest group of $\alpha$-amylases is in GH 13 with 109,801 protein sequences deposited as of March 2021.

Since $\alpha$-amylases are highly demanded in various industries, their bulk productions are therefore, of huge interest in the research discipline. In addition, most industrial processes are performed at non-physiological conditions encompassing elevated temperature, extreme $\mathrm{pH}$, high salinity, organic solvents, and surfactants, where some usages require specific substrates or products generated (Nigam, 2013; Sudan et al., 2018). Microbial $\alpha$-amylases with desirable properties are preferable since they can be natively isolated from wild type host, heterologously expressed in the recombinant host or engineered for the desired traits (Nigam, 2013; Lim, Oslan \& Oslan, 2020). 
80

81

82

83

84

85

86

87

88

89

90

91

92

93

94

95

96

97

98

99

100

101

102

103

104

105

106

107

108

109

110

111

112

113

114

115

116

117

118

119

Despite the long process of isolating native $\alpha$-amylases with desired traits from environmental sources, researchers have developed strategies in generating new $\alpha$-amylases which suit into industrial applications through modifications of certain regions / residues in the protein sequences of existing $\alpha$-amylases. Besides truncation and terminal fusion (Sharma et al., 2019), these techniques mainly include directed evolution and rational design, which are initially based on in vitro and in silico analyses, respectively. In addition, most enzyme engineering processes will equip both techniques where rational design firstly identifies a targeted region in the protein sequence based on in silico structural data, which is then mutated randomly via in vitro directed evolution (error prone PCR and DNA shuffling) (Sharma et al., 2019).

The tremendous industrial needs have urged the creation of newly engineered $\alpha$ amylases; however, limited efforts have been paid to uncover the thorough updated information on the published engineering strategies of microbial $\alpha$-amylases. Here, this review covers mainly the recent advancement on the manipulations of existing microbial $\alpha$-amylases for enhanced characteristics required by the industries. Therefore, this article is needed to provide better perceptions on the future enzyme manipulation studies with sufficient inputs from the previous works to the researchers in the academia and industries. It also highlights the importance of understanding the three-dimensional structure of $\alpha$-amylase in enzyme engineering to develop new microbial $\alpha$-amylases which fit sustainably into the industrial applications.

\section{Microbial $\alpha$-Amylases: Mechanisms of Action}

$\alpha$-Amylases catalyze the endo-hydrolysis of starch while $\beta$-amylases (E.C. 3.2.1.2; GH 14) catalyze the exo-hydrolysis. This difference in the position of polysaccharide hydrolysis is resulted from the two slightly varied but distinct mechanisms of action, namely retaining ( $\alpha$ amylases; Fig. 1A) and inverting ( $\beta$-amylases; Fig. 1B), where both involve the displacement(s) of nucleophiles (Koshland, 1953; Zhang et al., 2010).

$\alpha$-Amylase has a general five-step reaction mechanism which involves double nucleophilic displacement, giving the popularly known $\alpha$-retaining double displacement mechanism in hydrolyzing its substrate. There are two key amino acid residues which are usually a pair of acidic amino acids (aspartic acid and/or glutamic acid) separated at an approximately 5 $\AA$ distance (Zechel \& Withers, 2000). The first amino acid acts as a catalytic nucleophile (Fig. 1A) which attacks the anomeric center of the substrate while the second amino acid donates a proton to the glycosidic oxygen at the anomeric center, catalyzing the removal/departure of aglycone (ROH) (Zhang et al., 2010; Van Der Maarel et al., 2002).

An oxocarbenium ion-like transition state is formed during the glycosylation step before the addition of water molecular and aglycone departure. The proton donation of the second amino acid renders itself as a general base which subsequently catalyzes the second nucleophilic displacement in the deglycosylation step of the covalent glycosyl-enzyme intermediate. Both nucleophilic displacements before glycosylation and after deglycosylation steps involve the oxocarbenium ion-like transition states as aforementioned, thus the $\alpha$-retaining double displacement mechanism (Zhang et al., 2010, Zechel \& Withers, 2001). 
$120 \beta$-Amylases, however, catalyze the hydrolysis of starch into maltose inside the polysaccharide

121

122

123

124

125

126

127

128

129

130

131

132

133

134

135

136

137

138

139

140

141

142

143

144

145

146

147

148

149

150

151

152

153

154

155

156

157

158

159

chain (endo-). Although the key catalytic residues are similar with $\alpha$-amylases, which are commonly a pair of carboxylic acids, these acidic residues are distant from $6-12 \AA$ (McCarter $\&$ Withers, 1994; Zhang et al., 2010). The more distant acidic amino acids enable the accommodation of the water molecule and substrate at the active site, where the cleavage of scissile glycosidic linkage is performed via general-base catalyzed nucleophilic attack of water molecule on the anomeric center and general-acid-assisted aglycone departure (Zechel \& Withers, 2001; Fig. 1B). Compared to the retaining mechanism of $\alpha$-amylases, this inverting mechanism involves only a single nucleophilic step, where the nucleophile from the acidic amino acid attacks the water molecule which subsequently attacks the substrate's anomeric center.

\section{Survey methodology}

This review was produced based on the research articles published between 2000 and 2020 indexed in the Web of Science Core Collection, Scopus, Elsevier and Google Scholar databases. The search terms used were $\alpha$-amylase AND (mutagenesis OR engineering) AND (thermostable OR acid OR alkaline OR oxidative OR substrate OR product) AND NOT (nonhuman OR article OR metabolism). The keywords "nonhuman", "article" and "metabolism" were excluded in the literature search because the search results were not relevant to the microbial $\alpha$-amylases, especially the main scope of this review article. The reference lists of these articles were also screened for relevant papers which could possibly be missed out during the search. Only articles reporting on the engineering of microbial $\alpha$-amylases were included and discussed. Three exceptional articles published before the year 2000 were also included for the important research outputs. This review provides an overview on the advances of modifying microbial $\alpha$-amylases via protein engineering techniques to achieve longer half-life in high temperature, improved resistance (acidic, alkaline and oxidative) as well as enhanced substrate and product specificities.

\section{Microbial $\alpha$-Amylases for Industrial Applications}

Most industrial important enzymes especially $\alpha$-amylases are preferably isolated from microbial sources encompassing mainly the bacteria, yeasts and fungi due to the ease in genetic manipulations and bulk productions (Lim, Oslan \& Oslan, 2020). Therefore, native and recombinant $\alpha$-amylases have frequently been produced by or cloned into various microbial expression hosts including Bacillus subtilis (Trabelsi et al., 2019a), Enterococcus faecalis (Meruvu, 2019), Aspergillus clavatus (Shruthi, Achur \& Nayaka Boramuthi, 2020), Tepidimonas fonticaldi (Allala et al., 2019), Komatagaella phaffii (Trabelsi et al., 2019b; Wang et al., 2019) and Meyerozyma guilliermondii (Nasir et al., 2020).

\section{Microbial Enzymes Production and Purification}

$\alpha$-Amylases can be produced extracellularly or intracellularly by the microorganisms. While most heterologous proteins produced intracellularly in the obsolete Escherichia coli-based expression system form the insoluble fractions called inclusion bodies (IBs) (Singhvi et al., 
160

161

162

163

164

165

166

167

168

169

170

171

172

173

174

175

176

177

178

179

180

181

182

183

184

185

186

187

188

189

190

191

192

193

194

195

196

197

198

199

2020), the addition of signal peptides in the recombinant plasmids can resolve such issue in most bacteria. However, yeasts are favoured for industrial production of $\alpha$-amylases due to their simplicity as unicellular organisms with more similar post-translational modifications (PTMs) with higher level eukaryotes, where an in vitro process is needed for PTMs in bacterial expression systems (Vieira Gomes et al., 2018).

From the microbial fermentation products, the cells are usually separated from their spent media via centrifugation at cold temperature $\left(4{ }^{\circ} \mathrm{C}\right)$. The extracellular $\alpha$-amylases which are secreted into the fermentation media will present in the supernatants. The pelleted cells need to be ruptured to release the intracellular $\alpha$-amylases where the most frequently used method is sonication compared to others (ball milling, enzymatic cell wall removal, freezing-thawing, liquid shearing and osmotic shock) (Robinson, 2015). The ruptured cells are again pelleted, and the intracellular $\alpha$-amylases are extracted in the supernatants.

Following enzymes extraction, (partial) purifications are performed to yield the pure $\alpha$ amylases which are readily applied in industries. A recent study has reported on the usages of ammonium sulfate precipitation and anion exchange chromatography (AEX) using diethyl amino ethyl (DEAE) cellulose resin to purify a thermostable $\alpha$-amylase expressed in Bacillus sp. strain SP-CH7 with a 65.95-fold purification and 25.9\% yield (Priyadarshini \& Ray, 2019). Ammonium sulfate, being the most frequently equipped salt to precipitate enzymes, is added slowly into the crude enzymes to increase the hydrophobic interaction between $\alpha$-amylases and water with decreasing contact surface area of the enzymes with the solvent (water) (Lim, Oslan \& Oslan, 2020).

However, desalting step via dialysis is required to remove excessive salt from the partially purified $\alpha$-amylases for more accurate characterizations. Interestingly, Feng's research group (Xian et al., 2015) performed desalting via HiPrep 26/10 desalting column, resulting in higher enzyme recovery $(80.13 \%)$ compared to the dialysis-based desalting technique. While plant $\alpha$-amylases tend to be in two isoforms i.e., high and low isoelectric point (pI) (Ju et al., 2019), most microbial $\alpha$-amylases only exhibit low $\mathrm{pI}$ isoforms since the resins reported for microbial $\alpha$-amylases purification are anionic exchangers (DEAE and Q) (Sudan et al., 2018; Priyadarshini, Pradhan \& Ray, 2020). $\alpha$-Amylases can also be purified via ultrafiltration and gel filtration chromatography albeit salt precipitation and AEX.

Gel filtration chromatography (also known as size-exclusion chromatography) is usually equipped after salt precipitation and AEX as a desalting step despite its primary function to purify $\alpha$-amylases based on their sizes. Two-time ultrafiltration (using 100,000 and 30,000 molecular weight cut off membranes) and Sephadex G-100 were performed to purify a polyextremotolerant $\alpha$-amylase expressed in E. faecalis mercadA7 with $24 \%$ yield at 7.2 -fold purification (Meruvu, 2019). Interestingly, a recent study has reported on the purification of three native $\alpha$-amylases (known as Amy586) in B. subtilis strain US586 through a three-step purification encompassing heat treatment $\left(30 \mathrm{~min}\right.$ at $\left.55^{\circ} \mathrm{C}\right)$, acetone concentration and gel filtration (Superdex 200) with the final yield of only 10\% with 92.7-fold purification (Trabelsi et al., 2019a). 
200

201

202

203

204

205

206

207

208

209

210

211

212

213

214

215

216

217

218

219

220

221

222

223

224

225

226

227

228

229

230

231

232

233

234

235

236

237

238

239

Moreover, affinity chromatography, perhaps, is the most preferred purification method when $\alpha$-amylases are expressed recombinantly. Despite the large size of glutathione Stransferase (GST) tag i.e., $26 \mathrm{kDa}$ which is commonly used in E. coli-based expression vector (pGEX) (Kimple, Brill \& Pasker, 2013), polyhistidine $\left(\mathrm{His}_{6}\right)$ tag is preferably employed in immobilized metal affinity chromatography (IMAC) of $\alpha$-amylases. In 2015, Gandhi et al. reported on the single-step purification of His-tagged SR74 $\alpha$-amylase expressed in K. phaffii GS115 (previously known as Pichia pastoris) using $5 \mathrm{~mL}$ HiTrap IMAC FF with 52.6\% yield at 1.9-fold purification (Gandhi et al., 2015).

Surprisingly, hydrophobic interaction chromatography (HIC) has also been performed to purify fungal and bacterial $\alpha$-amylases using HiPrep 16/10 phenyl FF (Xian et al., 2015) and Phenyl-Sepharose column (Keskin \& Ertunga, 2017), respectively. Although a variety of methods are available to purify microbial $\alpha$-amylases, the ultimate aims of purifications are to achieve both high recovery yield and purification fold, besides providing the most accurate characterization of $\alpha$-amylases for industrial applications.

\section{Enzymes Characterizations for Industrial Applications}

Several microbial $\alpha$-amylase characterizations have been reported, encompassing optimum temperature, optimum $\mathrm{pH}$, thermal stability, $\mathrm{pH}$ stability, tolerances (salinity, detergents, and organic solvents). These characterizations are essential to evaluate and determine the applicability of the concerned $\alpha$-amylases in the wide industrial fields. In food and beverages industries, $\alpha$-amylases have been used in starch processing (saccharification and liquefaction; starch-to-ethanol conversion), break making, high fructose corn syrup (HFCS) formation, beer brewing and haze clarification in fruit juice.

$\alpha$-Amylases which involve in starch saccharification and liquefaction must be thermostable or hyperthermostable due to the elevated temperature during these processes (Lim, Oslan \& Oslan, 2020). The hydrolysis rates of $1 \%(\mathrm{w} / \mathrm{v})$ corn, wheat and potato starches at $16 \mathrm{~h}$ $\left(60{ }^{\circ} \mathrm{C}, \mathrm{pH} 7\right)$ were $57.52,49.61$ and $32.35 \%$ respectively when $1 \mathrm{U} / \mathrm{mg}$ starch of purified $\alpha-$ amylase expressed in B. amyloliquefaciens BH072 was used (Du et al., 2018; Table 1). Interestingly, a more powerful thermostable $\alpha$-amylase from Geobacillus sp. K1C recorded the degradation rates of $10 \%(\mathrm{w} / \mathrm{v})$ rice, wheat and potato starches at $88.1 \%, 90.3 \%$ and $81.1 \%$ respectively after $4 \mathrm{~h}$ incubation with $0.1 \mathrm{U} / \mathrm{mg}$ enzyme at $80^{\circ} \mathrm{C}$ and $\mathrm{pH} 6$ (Sudan et al., 2018).

Besides, three acid-stable $\alpha$-amylases isoforms expressed in B. subtilis strain US586 has been assessed for its application in the bread making industry (Trabelsi et al., 2019a). The $\alpha$ amylases (Amy586) supplementation $(0.06 \mathrm{U} / \mathrm{g}$ ) in flour not only increased the dough quality (elasticity : extensibility ratio $=0.5-1.2$ ), but also significantly decreased the bread hardness with enhanced cohesion and elasticity (Trabelsi et al., 2019a). The intermediate temperature stable (ITS) Laceyella sp. DS3 $\alpha$-amylases (AmyLa; wild type and recombinant) were said to be desirable in the baking industries as an antistaling agent while exhibiting the optimum temperature at $50{ }^{\circ} \mathrm{C}$ and $55^{\circ} \mathrm{C}$, respectively (El-Sayed et al., 2019). Nevertheless, $\alpha$-amylase supplementation was also expected to improve the texture, flavour and shelf-life of the bread. In 
240

241

242

243

244

245

246

247

248

249

250

251

252

253

254

255

256

257

258

259

260

261

262

263

264

265

266

267

268

269

270

271

272

273

274

275

276

277

278

279

addition, a Thermomyces dupontii $\alpha$-amylase (TdAmyA) expressed in $K$. phaffii was promising in maltose syrup production since the highest maltose percentage (approximately $52 \%$ ) could be achieved in a short hydrolysis time of liquefied starch at $8 \mathrm{~h}$ (Wang et al., 2019).

In the beverage industry, $\alpha$-amylases have been used to clarify fruit juices since a dark product may not be preferred by the consumers (Uzun, Demirci \& Akatin, 2018). A study had reported on the reduction of colour intensity of the raw apple juice $\left(\mathrm{OD}_{440 \mathrm{~nm}}\right)$ from 1.537 to 0.443 after $3 \mathrm{~h}$ incubation of $4.9 \mathrm{~mL}$ pasteurized apple juice with $0.1 \mathrm{~mL}(1 \mathrm{mg} / \mathrm{mL})$ purified $\alpha$ amylase expressed in Rhizoctonia solani AG-4 strain ZB-34 (Uzun, Demirci \& Akatin, 2018). Captivatingly, a metatranscriptomics study of Chinese Nong-flavour liquor starter has successfully mined a fungal extracellular thermostable $\alpha$-amylase (NFAmy13A) which exhibits optimum activity at $60{ }^{\circ} \mathrm{C}$ and $\mathrm{pH} 5.0-5.5$ (Yi et al., 2018). In addition, its prominent role in beer brewing and liquor starter had been evident with its highest substrate specificity towards amylopectin which was more abundantly detected in wheat material compared to amylose (Yi et al., 2018).

In detergent industry, the desirable traits of $\alpha$-amylases are more complex than other industries, encompassing being thermostable, alkaline-stable and stable towards various detergent components (oxidizing agents and surfactants). The crude $\alpha$-amylase expressed in $B$. mojavensis SA was proven to be tolerant towards sodium dodecyl sulfate (SDS), Tween 20, Tween 80 , Triton X-100, sodium perborate as well as reactive hydrogen peroxide $\left(\mathrm{H}_{2} \mathrm{O}_{2}\right)$ (Hammami et al., 2018). Nevertheless, the starch stain removal rate of purified alkaline $\alpha-$ amylase (AA7) expressed in Bacillus sp. strain SP-CH7 reduced insignificantly from $96.083 \%$ to 95.960\% when detergent was added, proving its compatibility in detergent industry while maintaining the brightness and softness of the tested cotton fabrics (Priyadarshini \& Ray, 2019). Notably, a cold-adapted, halophilic $\alpha$-amylase (Amy175) from Antarctic sea ice bacterium Pseudoalteromonas sp. M175 has been evident for its primary application in detergent industry where it retained more than $76.9 \%$ of amylolytic activity after one hour of incubation at $25{ }^{\circ} \mathrm{C}$ with all commercial laundry detergents tested (Wang et al., 2018a). It is also reported that the addition of Amy $175(12.6 \mathrm{U} / \mathrm{mL})$ with detergent exhibited better wash performance than the sole detergent, proving its huge potential as the detergent additive (Wang et al., 2018a).

While coating (sizing) with a gelatinous substrate (size) like starch is required to prevent breakage during the weaving process in the textile industry, desizing (removal of size-like starch) is needed to allow water and finishing agents absorbances without fiber damage (Mehta \& Satyanarayana, 2016). A cotton fabric desized with $1.8 \%$ partially purified $\alpha$-amylase expressed in Aspergillus luchuensis BS1 was found to exhibit 9.5\% weight loss when treated at $60{ }^{\circ} \mathrm{C}$ for 1 $\mathrm{h}$ as well as $5 \mathrm{sec}$ of wetting time and 8 rating in Tegewa analysis while employing iodine drop test (Sadhasivam et al., 2018).

Nonetheless, the $\alpha$-amylase expressed in B. subtilis TB1 had been reported to involve in the biodegradation and bioremoval of n-alkanes (in 1\% v/v n-paraffins) with 53\% reduction in residual hydrocarbons in the system with the presence of starch, a carbohydrate polymer (Karimi $\&$ Biria, 2016). In addition, the subsequent study (Karimi \& Biria, 2019) has evident the 
280

281

282

283

284

285

286

287

288

289

290

291

292

293

294

295

296

297

298

299

300

301

302

303

304

305

306

307

308

309

310

311

312

313

314

315

316

317

318

commercial $\alpha$-amylase was able to reduce the weight (48\%), tensile strength (87\%) of lowdensity polyethylene (LDPE)-starch blend samples as well as molecular weight $(70 \%)$ and viscosity (60\%) of LDPE, thus exhibiting a promiscuous cometabolic effect while biodegrading LDPE in the blends. Besides biodegradation, $\alpha$-amylases have also been used in feed industry to improve digestibility of animal feeds.

Importantly, the engineering of $\alpha$-amylase to improve its suitability in industrial applications is highly guided with its structural and sequence analyses despite the sole functions of directed evolution and rational design. Therefore, the understanding on the structural properties of $\alpha$-amylases is of utmost important before performing enzyme engineering for its biotechnological traits and benefits.

\section{Structural Properties of Microbial $\alpha$-Amylases}

The structure of a protein is more conserved compared to its sequence after evolutions. Hence, the dissection on microbial $\alpha$-amylase structural properties is crucial and essential prior to designing an existing enzyme with enhanced characteristics. As aforementioned, $\alpha$-amylases have been grouped into 4 distinct families encompassing GH 13, GH 14, GH 57 and GH 119 with GH 13 accommodating highest number of $\alpha$-amylases. Therefore, this section will discuss only on the structural properties of microbial $\alpha$-amylases which fall in GH13 in CaZy database based on a recently elucidated structure of $B$. paralicheniformis ATCC 9945a $\alpha$-amylase (BliAmy) (Božić et al., 2020).

A typical $\alpha$-amylase has a classical three-domain fold, namely Domain A (residues 3 103 and 206 - 396), Domain B (residues 104 - 205) and Domain C (residues 397 - 482) (Fig. 2A). N-terminal domain A, where the catalytic triad residues (D231, E261 and D328) were located, was also known as the catalytic domain possessing a central $(\beta / \alpha)_{8}$ TIM-barrel structure. Notably, domain B was extruded from domain A, consisting of two extended loops. The Cterminal domain $\mathrm{C}$ was, however, composed of a $\beta$-barrel with 8 antiparallel strands. This domain consisted of a Greek key motif which was attributed to substrate binding in Geobacillus thermoleovorans $\alpha$-amylase (Mehta \& Satyanarayana, 2014).

Furthermore, several surface-binding sites (SBS) were present in BliAmy despite having carbohydrate-binding module (CBM) as another starch-binding domain (SBD) reported.

However, only the SBS involving maltotetraose (G4) binding is selected and shown in Fig. 2A. Unlike CBM located usually at separate domains which connected to the $\mathrm{N}$ - or C-termini of the catalytic domain (Domain A) via a polypeptide linker, SBS was a non-catalytic site present mostly in the catalytic domain, which enhanced the starch-absorptivity level and subsequently increased the raw starch degradation rates (Baroroh et al., 2017; Božić et al., 2020). In BliAmy, the SBS which binds maltotetraose has two key amino acids F257 and Y358 (Fig. 2B) was shown to provide a hydrophobic platform for the carbohydrates while their substitutions with alanine resulted in 5-fold lower raw starch catalytic efficiency with more than 5.5-fold lower affinity compared to the wild type (Božić et al., 2020). 
The structural function of SBS has been validated when $\alpha$-amylase from Saccharomyces fibuligera R64 (Sfamy R64) was shown to exhibit low starch adsorptivity due to the absence of SBS (Yusuf et al., 2017). In addition, an acarbose molecule which was a typical inhibitor of $\alpha$ amylases, was also observed to bind in the SBS of B. stearothermophilus STB04 (Bst-MFAse; PDB ID: 6ag0) located in the active site (Xie et al., 2019a). Importantly, a pair of aromatic amino acid residues was found at each of the three SBSs in the Halothermothrix orenii $\alpha-$ amylase (AmyB), where the hydrophobic $\mathrm{CH} / \pi$-stacking interaction was prominently observed (Tan et al., 2008). Tetrasaccharide, $\beta$-cyclodextrin, and glucose were bound to SBS I (W488 and Y460), SBS II (W287 and W260) as well as SBS III (W310 and W306), respectively (Tan et al., 2008).

To date (March 2021), there have been 88 different CBM families established in the CAZy database (http://www.cazy.org/Carbohydrate-Binding-Modules.html) whereby 12 CBM families have been reported in the $\alpha$-amylases (E.C. 3.2.1.1) (Lombard et al., 2013). CBMs have been recognized as SBD in starch-hydrolyzing enzymes which include microbial $\alpha$-amylases (Baroroh et al., 2017), and most CBMs adopt a $\beta$-sandwich fold which is carbohydrates-binding (Janeček et al., 2019). The removal of CBMs in Eubacterium rectale (a butyrate-producing gut bacterium) $\alpha$-amylase has $\approx 40$-fold reduction in its enzymatic activity towards corn starch, highlighting the presence of CMBs in improving the catalytic function of the $\alpha$-amylase (Cockburn et al., 2018).

Interestingly, there are three types of CBMs classified based on their topology of the ligand-binding site, namely Type A (planar and hydrophobic surface which binds insoluble carbohydrates encompassing crystalline cellulose and chitin), Type B (variable loop sites, VLS and concave face sites, CFS which bind various glycans such as starch, mannans, galactans and xylans) as well as Type $\mathrm{C}$ (pocket which recognizes short-chain or exposed carbohydrates especially 1C-, 2C-, and 3C-carbohydrates) (Armenta et al., 2017; Campos et al., 2016). These interactions between the binding sites (CBM and/or SBS) are generally made up of hydrophobic interactions $(\mathrm{CH}-\pi)$ which involve the strictly conserved tryptophan, tyrosine and phenylalanine residues (Zagar et al., 2006), and subsequently supported by the formation of hydrogen bonds, especially in CMB Type B and C (Campos et al., 2016). However, the presence and number of CMBs in microbial $\alpha$-amylases vary within organisms despite the classical three-domain fold (Sidar et al., 2020).

While certain loops and secondary structures might contribute to the physicochemical properties of the enzyme, it is noteworthy that the protein-ligand interactions also played indispensable roles in stabilizing the $\alpha$-amylase structure. As illustrated in Fig. 2A, BliAmy possessed four metal ion ligands: two calcium ions $\left(\mathrm{Ca}^{2+}\right)$ and two sodium ions $\left(\mathrm{Na}^{+}\right)$(Božić et al., 2020). Two calcium ions (CaI-CaII) and a calcium ion (NaI) formed a metal triad which was in the interior of Domain B, while NaII resided between Domain A and Domain C.

Despite the often-reported $\mathrm{Ca}^{2+}-\mathrm{Na}^{+}-\mathrm{Ca}^{2+}$ linear metal triad (Offen et al., 2015), BstMFAse had the unprecedented $\mathrm{Ca}^{2+}-\mathrm{Ca}^{2+}-\mathrm{Ca}^{2+}$ triad (Xie et al., 2019a), where it had been used as the template to predict the $3 \mathrm{D}$ structures of both wild type and recombinant bacterial SR74 $\alpha$ - 
359

360

361

362

363

364

365

366

367

368

369

370

371

372

373

374

375

376

377

378

379

380

381

382

383

384

385

386

387

388

389

390

391

392

393

394

395

396

397

398

amylases through homology modeling strategy (Lim et al., 2020). However, NaII in BliAmy replaced the calcium ion which had been reported to be located between Domain A and Domain C, where its role was not described (Božić et al., 2020). On the contrary, the calcium ion (CaIV) in SR74 $\alpha$-amylase was hypothesized to involve in substrate specificity and catalytic activity of the enzyme, by bridging Domain A and Domain C (Lim et al., 2020).

Besides the wide availability of $\alpha$-amylases sequences, the understanding of their structural properties should not be underexplored. In facts, protein engineering relies heavily on both sequential and structural information of the existing $\alpha$-amylases, by means of directed evolution, rational design or the combination of both (Sharma et al., 2019).

\section{Engineering of Microbial $\alpha$-Amylases for Industrial Applications}

The processes in the industries often involve harsh conditions. Several important features encompassing thermostability, $\mathrm{pH}$ tolerance, substrate and product specificities as well as oxidative stability, are therefore, favoured in the industries. Being the industrial important enzymes, $\alpha$-amylases have extensively been studied in terms of their categorizations, sequences and structures. The ample knowledge on $\alpha$-amylases have allowed researchers to modify and engineer various native and recombinant $\alpha$-amylases for their beneficial traits in the industrial applications (Table 2).

\section{Engineered Microbial $\alpha$-Amylases with Increased Thermostability}

Over the decades, various microbial $\alpha$-amylases have been engineered for elevated thermostability via several methods including directed evolution, rational design and others. These studies which have evident the indispensable roles of disulphide linkages, hydrogen bonds, metal ions, salt bridges, non-polar interactions and stabilization or removal of flexible or extended loops in $\alpha$-amylases resistance towards thermal inactivation will be described and discussed.

A site-directed mutagenesis (SDM) in a novel Flavobacteriaceae sinomicrobium $\alpha$ amylase (FSA) had been performed to introduce a disulphide bridge in its Domain $\mathrm{C}$ based on the multiple sequence alignment (MSA) with $\alpha$-amylases in another clade of Flavobacteriaceae genus (Li et al., 2014). By substituting both $\mathrm{K} 415$ and S450 in the wild type FSA with cysteines, elevated half-life $\left(t_{1 / 2}\right)$ at $50{ }^{\circ} \mathrm{C}$ from 25 to 55 min with an optimum activity at $55^{\circ} \mathrm{C}$ was observed besides the thermal inactivation reversal at $100{ }^{\circ} \mathrm{C}$ with more than $50 \%$ residual activity detected for the mutant FSA ( $\mathrm{Li}$ et al., 2014). The stability retainment under the extreme conditions of mutant FSA was preferred in the industrial production of food, paper, bioethanol, textiles and detergents although the promising results on these applications were not established in this study.

Besides the intra-domain disulphide bridge, an inter-domain disulphide linkage was introduced between the Domain A and Domain C of a yeast Saccharomycopsis fibuligera R64 $\alpha$ amylase expressed in K. phaffii KM71H (Sfamy01) by replacing both S336 and S437 with cysteine residues (Natalia et al., 2015). Albeit the suggested mutation candidates were S336 and 
399

400

401

402

403

404

405

406

407

408

409

410

411

412

413

414

415

416

417

418

419

420

421

422

423

424

425

426

427

428

429

430

431

432

433

434

435

436

437

438

S478, the location of S478 in a $\beta$-turn and its stabilizing interactions with the $\beta$-strands had led to the mutation of another loop-residing serine (S437) which did not contribute to $\beta$-sheets arrangement. The mutant $\alpha$-amylase (Sfamy02) with improved hydrophobic interaction between two domains was shown to maintain $60 \%$ of its residual activity compared to the substantial decline in Sfamy01, therefore suitable for raw-starch degradation in the rice and cassava fermentation (Natalia et al., 2015).

In spite of the increased activity (3.2\%) detected by introducing a new disulphide linkage in FSA at E200C and $\mathrm{H} 201 \mathrm{C}$, enhanced ligand-dependent thermostability i.e., $\mathrm{Ca}^{2+}$ and $\mathrm{Zn}^{2+}$ was detected after the incubation at $50{ }^{\circ} \mathrm{C}$ for $30 \mathrm{~min}$ when $\mathrm{E} 204 \mathrm{G}$ and $\mathrm{C} 214 \mathrm{~S}$ mutations were performed (Yin et al., 2017). Nonetheless, the improvement in thermostability $\left(t_{1 / 2}\right.$ at $\left.95^{\circ} \mathrm{C}\right)$ at 26-fold ( $\mathrm{Ca}^{2+}$-absent) and 5-fold $\left(\mathrm{Ca}^{2+}\right.$-present) was observed when the loop deletion of I181 and G182 ( $\triangle \mathrm{IG})$ coupled with N193F and S242A were performed on the maltohexaose-forming $\alpha$ amylase from B. stearothermophilus (AmyMH) (Li, Duan \& Wu, 2016).

These findings further evident that the enhancement of ligand binding and flexible extended loop deletion may improve thermostability of the $\alpha$-amylases while suggesting the mutant AmyMH $(\Delta \mathrm{IG} / \mathrm{N} 193 \mathrm{~F} / \mathrm{S} 242 \mathrm{~A})$ is promising for industrial starch liquefaction. In addition, loop deletion ( $\triangle \mathrm{R} 179-\mathrm{G} 180)$ was also proven to enhance the thermostability of another $\alpha$ amylase from B. stearothermophilus (AmyS) by increasing the $t_{1 / 2}$ at $100{ }^{\circ} \mathrm{C}$ from 24 min to 33 $\min$ (Gai et al., 2018).

Nevertheless, a 9-fold improvement on the thermostability $\left(t_{1 / 2}\right.$ at $\left.95{ }^{\circ} \mathrm{C}\right)$ of $B$. licheniformis $\alpha$-amylase was recorded by increasing number of hydrogen bonds and salt bridges through the mutations of loop residues (S187D and N188T) and an adjacent residue (A269K) (Li et al., 2017). Such strategy was also equipped by a previous study when the Q294H mutation within the catalytic domain (Domain B) of Geobacillus sp. SK70 $\alpha$-amylase was performed to increase the optimum temperature $\left(55^{\circ} \mathrm{C}\right.$ to $\left.60^{\circ} \mathrm{C}\right)$ and thermostability $\left(t_{1 / 2}\right.$ at $60{ }^{\circ} \mathrm{C}$ from $35 \mathrm{~min}$ to $85 \mathrm{~min}$ ) based on a semi rational resign approach (Sulong et al., 2015).

In addition, a rationally engineering strategy was performed to introduce V260I mutation near to the central $\beta$-strands of $B$. subtilis CN7 $\alpha$-amylase's TIM barrel (Wang et al., 2020). The increased melting $\left(T_{\mathrm{m}} ; 7.1^{\circ} \mathrm{C}\right)$ and half-inactivation temperatures $\left(4.9^{\circ} \mathrm{C}\right)$ were attributed to the extra 8 weak Van de Waals (VDW) contacts within the central $\beta$-strands (Wang et al., 2020). The choices of both mutation candidate and replacing residue are crucial to introduce certain polar or non-polar linkages through mutation, where the comprehensive knowledge on amino acid residues is essential.

Notably, a cold-adapted but thermolabile $\alpha$-amylase expressed by the Antarctic ciliate protozoon Euplotes focardii (EfAmy) had been mutated at the surface loops of Domain A (T350P) and B (E166P/ S185P) as well as the residues (V212T/V232T) near to the catalytic site (Yang et al., 2017). Such SDM was multiple sequence alignment (MSA)-assisted where both mesophilic Euplotes crassus $\alpha$-amylase (EcAmy) and A. oryzae TAKA $\alpha$-amylase were compared for protein secondary structure analysis. The mutant with combined SDM exhibited higher optimum temperature $\left(30^{\circ} \mathrm{C}\right)$ compared to its wild type $\left(25^{\circ} \mathrm{C}\right)$ with 1.8 -fold increase in 
439 its $t_{1 / 2}$ at $50{ }^{\circ} \mathrm{C}$, without affecting its optimum $\mathrm{pH}$ (Yang et al., 2017). These substitutions to 440 proline and valine residues had conferred a higher rigidity to the thermolabile EfAmy through the 441 introduction of more polar hydrogen bonds. Such enhanced properties of rational-designed 442 EfAmy might favour its usage in detergent, food and textile industries, which worth to be 443 explored and evident further by the group of researchers.

444 Interestingly, chimerism which involves truncation and terminal fusion is perhaps the 445 most special engineering strategy compared to the common directed evolution and rational 446 design. A chimeric $\alpha$-amylase created using the truncated B. acidicola (Ba-amy) with the partial $447 \mathrm{~N}$ - and C-termini of $G$. thermoleovorans (Gt-amy) $\alpha$-amylases was proven to exhibit higher 448 thermostability and catalytic efficiency (Parashar \& Satyanarayana, 2016). The acquisition of a

449

450

451

452

453

454

455

456

457

458

459

460

461

462

463

464

465

466

467

468

469

470

471

472

473

474

475

476

477 better functioning starch binding domain (SBD) from the C-terminal of Gt-amy and the increase in $\beta$-sheet content in the circular dichroism (CD) results of the third chimer (ch3) might contribute to the improved catalytic efficiency and the increase of $t_{1 / 2}$ from $5 \mathrm{~min}$ to $15 \mathrm{~min}$ at 90 ${ }^{\circ} \mathrm{C}$ when expressed in E. coli (Parashar \& Satyanarayana, 2016). Captivatingly, a 10.7-fold increment in $\alpha$-amylase (Ba-Gt-amy) titre expressed in a multi-copy $K$. phaffii clone and its attractive physicochemical properties have made it suitable for baking and sugar syrup industries (Parashar \& Satyanarayana, 2017).

\section{Engineered Microbial $\alpha$-Amylase with pH Tolerance and Stability}

Although rational design has frequently been used to engineer the microbial $\alpha$-amylases for better $\mathrm{pH}$ tolerance and stability, error prone PCR (epPCR) and site-directed mutagenesis (SDM) are also performed to achieve the similar effect. An epPCR was conducted by Liu's group (Huang et al., 2019) to generate a mutant library with 2,300 clones, where G81R was found to retain $10 \%$ of its residual activity after incubating at $\mathrm{pH} 4.5$ for $40 \mathrm{~min}$ when the wild type was already inactivated. The mutation from glycine (non-polar) to arginine (positively charged) in $B$. licheniformis $\alpha$-amylase (BLA) stabilized the negatively charged D231 and decreased its $\mathrm{pKa}$ (Huang et al., 2019).

The $\mathrm{pKa}$ reduction in the nucleophilic catalytic residue (D174) was also observed when $\mathrm{N} 271 \mathrm{H}$ was introduced to B. subtilis Ca-independent $\alpha$-amylase (Amy7C) (Wang et al., 2018b). This study by Zhao's group (Wang et al., 2018b) had utilized both rational design and sitedirected mutagenesis and subsequently evident that A270K/N271H double mutant exhibited 2unit decline in optimum $\mathrm{pH}(\mathrm{pH} 4.5)$ with approximately 3.94-fold improvement in catalytic efficiency. In addition, the $\mathrm{pH}$ range at the acidic limb was found to be shifted to $\mathrm{pH} 3.5$ with more than $75 \%$ residual activity.

Similar strategy to reduce the $\mathrm{pKa}$ of nucleophile and hydrogen donor in catalytic residues was performed through the SDM of H293R/H316R/H327R in BLA, resulting in the triple mutant's ability to maintain $31 \%$ of residual activity at $\mathrm{pH} 4.5$ and $70{ }^{\circ} \mathrm{C}$ for $40 \mathrm{~min}$ (Liu et al., 2017). Interestingly, loop deletion is not only capable of increasing the enzyme thermostability, but a study concerning the deletion of the flexible loop ( $\triangle \mathrm{R} 179-\mathrm{G} 180)$ in $B$. 
478

479

480

481

482

483

484

485

486

487

488

489

490

491

492

493

494

495

496

497

498

499

500

501

502

503

504

505

506

507

508

509

510

511

512

513

514

515

516

517

stearothermophilus $\alpha$-amylase (AmyS) also shown its ability to improve the acid-resistance of AmyS to $\mathrm{pH}$ 4.5-6.0 with decreased optimal pH at pH 5.5 (Gai et al., 2018).

Nevertheless, the formation of addition hydrogen and salt linkages might also improve the acid resistance of an $\alpha$-amylase besides its thermostability. This was proven when a MSAbased V174R SDM was introduced to a yeast Rhizopus oryzae $\alpha$-amylase (ROAmy), whereby the mutant exhibited an improvement in thermostability $\left(t_{1 / 2}\right.$ at $\left.55^{\circ} \mathrm{C}\right), \mathrm{pH}$ resistance $\left(t_{1 / 2}\right.$ at $\mathrm{pH}$ 4.5) and catalytic efficiency $\left(\mathrm{k}_{\mathrm{cat}} / \mathrm{K}_{\mathrm{m}}\right)$ on soluble starch at 2.52-, 2.55- and 1.61-fold, respectively (Li, Yang \& Tang, 2020). In addition, a previous site-saturation mutagenesis was also performed on H286 of ROAmy (Li et al., 2018). The mutant H286E exhibited a 6.43-fold improvement in half-life (from $57.28 \mathrm{~min}$ to $66.65 \mathrm{~min}$ ) at $\mathrm{pH} 4.5$, which was correlated to its reduced optimum $\mathrm{pH}$ from $\mathrm{pH} 5.5$ (wild type) to $\mathrm{pH} 4.5$ (H286E mutant) (Li et al., 2018).

These engineered microbial acid-resistant $\alpha$-amylases are promising and suitable for starch liquefaction and saccharification industries since both processes occur at different $\mathrm{pH}$ ranges (pH 5.8-6.2 and pH 4.2-4.5, respectively) (Wang et al., 2018b). Albeit the importance of alkaline-resistant $\alpha$-amylases in detergent industry, it is noteworthy that the latest microbial $\alpha$ amylase engineering for its alkaline tolerance was reported by Chen's group (Deng et al., 2014). The group applied structure-based rational design for systems engineering of Alkalimonas amylolytica $\alpha$-amylase, whereby the triple mutant (H209L/Q226V/P477V) exhibited higher optimum $\mathrm{pH}(\mathrm{pH} 10.0)$ and broader $\mathrm{pH}$ range ( $\mathrm{pH}$ 6.0-12.0) compared to its wild type ( $\mathrm{pH} 9.5$; pH 7.0-11.0) (Deng et al., 2014).

Nonetheless, these studies have successfully proven that the usage of rational design, directed evolution or combination of both are powerful to modify, engineer and generate new $\alpha$ amylase mutants with enhanced acid or alkaline tolerance, which are beneficial in industrial applications.

\section{Engineered Microbial a-Amylases with Altered Substrate and Product Specificities}

Microbial $\alpha$-amylases with specific product specificity are favourable for food industry especially in starch conversion. However, the engineering of these $\alpha$-amylases for altered substrate specificity was scarce. Although many SDM studies had elucidated various residues with significant roles in different hydrolytic activities of $\alpha$-amylases (Svensson, 1994), only a very early study showed the K209R mutant of $A$. oryzae $\alpha$-amylase (Taka-amylase A; TAA) exhibited reduced and increased specificities towards starch and $p$-nitrophenylmaltoside (G2PNP) respectively, which involved the activity switch from $\alpha$-amylase to maltosidase (Nagashima et al., 1992). Therefore, activity switch, substrate specificity and product specificity (hydrolysis pattern) are closely related, although substrate specificity is often neglected in most studies.

As aforementioned, SBS and CBM are important in starch (and other insoluble substrates) adsorptivity and catalytic activity of microbial $\alpha$-amylases. Although CBMs have been fused with other carbohydrases (Furukawa et al., 2013; Zhang et al., 2013), microbial $\alpha$ - 
518 amylases have not been designed and verified in vitro on the fusion of CBM and/or SBS to alter 519 their substrate specificity. Notably, while the CBMs are often linked to the catalytic domain via a 520 polypeptide linker, Zhang et al. (2017) has reported the increase of substrate specificity towards 521 soluble starch (72.8\%), glycogen (69.3\%), dextrin (74.4\%), $\gamma$-cyclodextrin $(65.3 \%)$, and raw 522 starch (83.1\%) when CBM20 was linked to the Domain C of Talaromyces leycettanus 523 JCM12802 $\alpha$-amylase (Amy13A) via a 21-peptide linker homologous to an acid-stable $\alpha$ -

524

525

526

527

528

529

530

531

532

533

534

535

536

537

538

539

540

541

542

543

544

545

546

547

548

549

550

551

552

553

554

555

556

557 amylase (asAA) from Aspergillus kawachii (Kaneko et al., 1996).

Notably, a site-directed mutagenesis study by Amalia et al. (2016) had shown that the Y401W mutation of the $\alpha$-amylase from Saccharomycopsis fibuligera R64 (mSfamyR64) had caused $\approx 10 \%$ increase in specificity towards soluble ( 7.1 to $7.8 \mathrm{U} / \mathrm{mL})$ and raw $(4.5$ to $4.9 \mathrm{U} / \mathrm{mL})$ starches compared to its wild type (rSfamyR64). Although such improvement of activity was proposed to be contributed by stronger interaction with the starch substrates, both the wild type and mutated SfamyR64 did not adsorb onto the insoluble raw starch, a desired characteristic portrayed by microbial $\alpha$-amylases when CBM and/or SBS were present (Amalia et al., 2016).

To this end, the similar research group has adopted computational analysis to design and simulate the mutated SfamyR64 in silico. Yusuf et al. (2017) has evident the lacking of SBS in SfamyR64 and therefore mutating two hydrophilic amino acid residues to hydrophobic residues (S383Y/S386W) to introduce an SBS in the C-domain of SfamyR64. Molecular dynamic (MD) study (20 ns) and pairwise decomposition of interaction energy between maltose and SBS had proven the amelioration of the dynamics and binding affinity $(86.5 \%$ increase in interaction energy) of mutant SBS to the substrate, which made it comparable to the positive control (Aspergillus niger $\alpha$-amylase) (Yusuf et al., 2017).

Recently, Baroroh et al., (2019) have extended the MD study up to $100 \mathrm{~ns}$, observing that the maltose substrate was leaving the SBS at $20 \mathrm{~ns}$ for $12 \AA$ away from the initial coordinate and surprisingly for $146 \AA$ at $100 \mathrm{~ns}$. The group has therefore developed a mutant with seven substitutions (S383Y/S386W/N421G/S278N/A281K/Q384K/K398R) and an insertion of a fourresidue flexible loop (G400_S401insTDGS) to ensure better starch adsorptivity and affinity $(36.6 \%)$ as evaluated via the molecular generalized Born surface area (MM/GBSA) method (Baroroh et al., 2019). N421G reduced the stearic hindrance of the arginine residue towards W386 which was supposed to interact with the substrate in the positive control.

A281 and Q384 which were positioned above the SBS provided extra cavity for the substrate movement due to the smaller alanine residue and lack of extra hydrogen bonds. Hence, these two residues were replaced with lysine (A284K/Q384K) together with K398R (located below the SBS) to enhance the SBS affinity towards substrate through stronger hydrophobic interactions and hydrogen linkages. Nevertheless, the four-residue loop insertion (G400_S401insTDGS) also increased the number of hydrogen bonds, stabilizing the SBS structure in SfamyR64 (Baroroh et al., 2019). However, the latest in vitro engineering of microbial $\alpha$-amylases on substrate affinity and specificity was reported by Amalia et al. (2016) and Zhang et al., (2017). Therefore, such engineering deserves more attention from the researchers in the future. 
558

559

560

561

562

563

564

565

566

567

568

569

570

571

572

573

574

575

576

577

578

579

580

581

582

583

584

585

586

587

588

589

590

591

592

593

594

595

596

A site-saturation mutagenesis study (Li et al., 2018) had revealed on the higher affinity of ROAmy mutants H286L and H286M towards both maltotriose (G3) and soluble starch, which were correlated with the high-level production of maltose as end-products. Based on the molecular docking analysis, such phenomenon was attributed to the new non-polar contacts formed between the hydrophobic residues (leucine and methionine) with G3 at the non-reducing end (subsite -1) whereby extra hydrogen bonds could be formed between two more amino acid residues (Li et al., 2018).

In addition, maltohexaose (G6) specificity was also enhanced in the Bst-MFAse mutants (G109N, G109D, G109F) with G6 production from starch at 36.1, 42.4 and 39.0\% compared to only $32.9 \%$ in wild type (Xie et al., 2020). Through homology modelling analysis, the group (Xie et al., 2020) discovered that extra interactions (hydrogen bonds or hydrophobic interaction) were formed between the replaced residues and the substrate at subsite -6 , promoting the hydrolysis pattern from starch to G6 by the MFAse (Fig. 3). On the contrary, a previous study by the group presented that the Bst-MFAse mutants (W139A, W139L, W139Y) exhibited significant increase in maltopentaose (G5) production and aglycone-productive binding but had counter effect on maltohexaose (Xie et al., 2019b). It was suggested by the authors that the aromatic stacking between W139 and the substrate could control Bst-MFAse's product specificity and its oligosaccharide hydrolysis pattern.

Besides, a rational engineering of B. subtilis CN7 $\alpha$-amylase (Wang et al., 2020) was performed to generate 5 mutants (Y204F, Y204I, Y204V, V260I, V260L) with altered product specificities. In the study, all created mutants were found to produce more glucose (G1) than maltose (G2), with Y204V as exception. Interestingly, Y204F exhibited no G3 production, while Y204V produced G2, G3 and G5 without releasing any G1 and maltotetraose (G4) (Wang et al., 2020). The abolished hydrolysis to produce $\mathrm{G} 1$ as the final hydrolytic product had convert this typical $\alpha$-amylase to a novel MFAse which was preferred in bread and high-fructose corn syrup (HFCS) industries (Pan et al., 2017). However, it is worth mentioning that both Y204 and V260 were present in the $\beta$-strands of central TIM-barrel which contributed to the $\alpha$-amylase catalytic ability.

While some $\alpha$-amylases also possess transglycosylation activity, such activity is responsible for G3 formation which is undesired for high maltose syrups industry (Mehta \& Satyanarayana, 2016). To enhance the ratio of hydrolysis to transglycosylation in $\alpha$-amylases, several strategies encompassing the control of water accessibility, reduction of steric interference, improvement of acceptor molecule binding and modulation of catalytic nucleophile $\mathrm{pK}_{\mathrm{a}}$ could be performed (Abdul Manas, Md. Illias \& Mahadi, 2018). One such example is the SDM of acceptor binding subsite +2 in $B$. stearothermophilus maltogenic amylase by replacing W177 with phenylalanine $(\mathrm{F})$, tyrosine $(\mathrm{Y})$, leucine $(\mathrm{L})$, asparagine $(\mathrm{N})$ and serine $(\mathrm{S})$, which reported on the reverse-proportionate relationship between transglycosylation activity and the hydrophilicities of the replaced residues (Sun et al., 2016). With the increased hydrophilicity at subsite +2 , water molecule was more readily bound to promote $\mathrm{G} 2$ production through 
597 hydrolysis, whereby W177S mutant was most promising and superior for industrial application 598 (Sun et al., 2016).

599

600

601

\section{Engineered Microbial $\alpha$-Amylases with Increased Oxidative Stability}

602

Oxidative stability is an important yet highly preferred property for the $\alpha$-amylases to be utilized

603 in detergent industry. Cysteine and methionine residues which had sulfhydryl group (R-SH) had

604 been determined as two most oxidation prone residues in $\alpha$-amylases (Brosnan, Kelly \& Fogarty,

605 1992). While most cysteine residues form disulphide bridge to increase $\alpha$-amylase's stability,

606 more studies had been performed to mutate methionine to other oxidative-resistant residues as

607 first exemplified in B. licheniformis $\alpha$-amylase (BLA) (Brzozowski et al., 2000) and Bacillus sp. strain KSM-1378 $\alpha$-amylase (AmyK) (Igarashi, Hagihara \& Ito, 2003).

An SDM study (M197A) had generated a G. stearothermophilus US100 $\alpha$-amylase

609 mutant (AmyUS100/DI214, G215/M197A) with 70\% residual activity after 60 min of $1.8 \mathrm{M}$

610 hydrogen peroxide $\left(\mathrm{H}_{2} \mathrm{O}_{2}\right)$ treatment at $60{ }^{\circ} \mathrm{C}$ (Khemakhem et al., 2009). Similarly, the corresponding methionine residue of AmyUS100 in the truncated Bacillus sp. strain TS-23 $(\mathrm{BAC} \triangle \mathrm{NC})$ was mutated (M231L), resulting in mutants which retained more than $96 \%$ original activity in the presence of $500 \mathrm{mM} \mathrm{H}_{2} \mathrm{O}_{2}$ (Chi et al., 2010). Nevertheless, a structural-based SDM study (M145L, M214L, M229L, M247L, M317L) of Alkalimonas amylolytica $\alpha$-amylase had shown the mutations of these near-to-active-site methionine residues had enhanced oxidative stability, with M247L mutant exhibiting the highest resistance (72\%) (Yang et al., 2012).

618 The subsequent research by Chen's group (Yang et al., 2013a) had generated 85 multiple

619 mutants based on 8 single mutants with enhanced oxidative stability, where an outstanding multiple mutant (M145I-214A-229T-247T-317I) had exhibited 5.4-fold improvement in oxidative stability at $91.3 \%$ of original activity when incubated with $500 \mathrm{mM} \mathrm{H}_{2} \mathrm{O}_{2}$ for $1 \mathrm{~h}$. Interestingly, the $A$. amylolytica $\alpha$-amylase with its $\mathrm{N}$-terminal fused with an highly hydrophilic

623 oligopeptide which formed $\beta$-sheet structure in aqueous solution had 2.7-fold increase in oxidative resistance while retaining $54 \%$ of its original activity after 30 min incubation with 500 $\mathrm{mM} \mathrm{H}_{2} \mathrm{O}_{2}$ (Yang et al., 2013b). Such observation was justified with the further distance of M247 with the catalytic residues (D278 and D340) in the mutant compared to its wild type, as previously exemplified (Yang et al., 2012, 2013b).

The latest investigation on engineering of $\alpha$-amylases for enhanced oxidative stability,

628

629

630

631

632

633

634

635

636 was perhaps in 2013. However, this study (Ozturk et al., 2013) had proven that the mutation at near-to-active-site methionine residue (M55A) was more significant than mutation of solventaccessible methionine residues (M43A + M44A) in terms of oxidative stability, where both types of methionine residues were proven to be oxidation prone (Lin et al., 2003; Yang et al., 2012). This statement was justified when M55A mutant retained $50 \%$ of its initial activity in the presence of $100 \mathrm{mM} \mathrm{H}_{2} \mathrm{O}_{2}$, compared to double mutant (M43A + M44A) at 39\% (Ozturk et al., 2013). Nevertheless, such investigations and engineering to improve oxidative stability of microbial $\alpha$-amylases remain underexplored and should not become obsolete (latest report in 2013; Table 2) due to its great interests and advantages in detergent industry. 


\section{Discussions}

639 Microbial $\alpha$-amylases remain as valuable assets in the industries for their favourable properties

640 encompassing thermostability, $\mathrm{pH}$ stability and tolerance, product and substrate specificities as

641 well as oxidative stability. These native and recombinant $\alpha$-amylases can be produced

642 intracellularly or extracellularly, purified and further characterized for their important

643 biochemical properties. Although there have been a wide variety of purification techniques

644 available, microbial $\alpha$-amylases are often purified at higher recovery and purification fold using

645 affinity chromatography when they are expressed recombinantly with the frequently fused

646 polyhistidine tags (Lim, Oslan \& Oslan, 2020).

647 The purified microbial $\alpha$-amylases can be extensively characterized for industrially

648 favoured traits. These characteristics are mutually reflective to the 3D structural properties.

649 Albeit the classical three-domain fold of most microbial $\alpha$-amylases, the presence of CMB

650 (Armenta et al., 2017) and/or SBS (Baroroh et al., 2017) is crucial for their substrate and product

651 specificities. The interactions within the amino acid residues in the enzymes, encompassing salt

652 bridges, disulfide linkages, hydrogen bonds and hydrophobic interactions are undeniably

653 attributed to their biochemical properties, especially the temperature and $\mathrm{pH}$ optimal, as well as

654 the stability towards extreme conditions.

655 Although these microbial $\alpha$-amylases might initially exhibit the biochemical traits which

656 are preferred for industrial applications, the more powerful enzymes have continuously been

657 sought. Greater abilities to withstand the harsh environments are advantageous for more

658 specifically targeting or widening of their usages in a single or several different industries,

659 respectively. In brief, enzymes having higher optimum temperature and thermostability as well

660 as adequate substrate and product specificities are favourable in the food and beverages

661 industries. In detergent industry, however, resistance to extreme $\mathrm{pH}$ and oxidation is crucial for

662 the enzymes to remain functional when they are added as the detergent additives. While the

663 protein engineering techniques have been becoming more advanced, the frequently used

664 strategies to modify microbial $\alpha$-amylases are rational design, directed evolution, truncation and

665 terminal fusion (Sharma et al., 2019).

666 Rational design is an in silico approach to determine the residue(s) or regions to be

667 mutated, which is generally based on an MSA within gene sequences of the congeneric species

668 (Yang et al., 2017). Besides MSA, rational design can also be a systematic structure-based

669 strategy (Yang et al., 2013a) which is a targeted engineering compared to directed evolution

670 (error prone PCR and DNA shuffling). Directed evolution is essentially a labour-intenstive and

671 time-consuming approach to screen all the mutants for the improved and desired biochemical

672 properties. The engineering works reviewed in this article have been evident to enhance the

673 biochemical properties of microbial $\alpha$-amylases encompassing longer half-life at extreme

674 temperature $\left(100^{\circ} \mathrm{C}\right), \mathrm{pH}\left(\mathrm{pH} 3.5\right.$ and 10.0) and oxidative stress $\left(1.5 \mathrm{M} \mathrm{H}_{2} \mathrm{O}_{2}\right)$ as well as

675 enhanced specificities on substrates $(>65.3 \%)$ and products $(42.4 \%)$. Therefore, these

676 ameliorations of microbial $\alpha$-amylases characteristics have successfully proven that the protein 
677 engineering techniques are indeed promising and worth exploring to generate new yet valuable

678 mutants for better suitability in various industrial applications.

679

\section{Conclusions}

681 To conclude, the engineering of microbial $\alpha$-amylases should be a continuous and sustained

682 effort to design the enzymes for their pertinent roles in various industrial applications. Therefore,

683 a review covering the current protein engineering techniques and design rationales is needed to

684 provide conceptual advances to the researchers. The critical points of mutations are highly

685 dependent on the respective $\alpha$-amylases. Disulfide bridge establishments by converting polar

686 amino acids into cysteines is observed for enhanced thermostability. Residues substituted into

687 basic amino acids (lysine, histidine and arginine) are remarkable for acidic resistance.

688 Hydrophobic residues for hydrophobic platform in the CBM/SBS are preferred for improved

689 substrate specificities. Oxidation-prone methionine residues are often substituted with non-polar

690 residues (alanine, leucine, isoleucine and phenylalanine) to enhance its oxidative stability.

691 Notably, the engineering investigations on ameliorated substrate specificity and oxidative

692 stability are limited and deserve further exploration. It could be conducted as previously

693 performed but inferable from other biocatalysts (lipases, proteases and others). Cross-

694 disciplinary collaborations among researchers having the expertise of structural biology,

695 metabolism and fermentation can be established to produce microbial $\alpha$-amylases with enhanced

696 properties in industrial-scale bioreactors. Thus, microbial $\alpha$-amylases with various preferred

697 characteristics are possible with careful scrutinization of their sequential, structural and

698 evolutionary analyses.

699

700

Acknowledgements

701

Sincere thanks to all members of Enzyme and Microbial Technology (EMTech) Research Centre and Enzyme Technology Laboratory, Institute of Bioscience, Universiti Putra Malaysia.

703

704

\section{References}

705

706

707

708

709

710

711

712

713

714

715
Abdul Manas NH, Md. Illias R, Mahadi NM. 2018. Strategy in manipulating transglycosylation activity of glycosyl hydrolase for oligosaccharide production. Critical Reviews in Biotechnology 38:272-293. DOI: 10.1080/07388551.2017.1339664.

Allala F, Bouacem K, Boucherba N, Azzouz Z, Mechri S, Sahnoun M, Benallaoua S, Hacene H, Jaouadi B, Bouanane-Darenfed A. 2019. Purification, biochemical, and molecular characterization of a novel extracellular thermostable and alkaline $\alpha$-amylase from Tepidimonas fonticaldi strain HB23. International Journal of Biological Macromolecules 132:558-574. DOI: 10.1016/j.ijbiomac.2019.03.201.

Amalia R, Ismaya WT, Puspasari F, Hasan K, Subroto T, Natalia D, Soemitro S. 2016. Heterologous Expression of $\alpha$-amylase from Saccharomycopsis fibuligera $\mathrm{R} 64$ and its Tyr401Trp mutant in Pichia pastoris. Microbiology Indonesia 10:4. DOI: 10.5454/mi.10.1.4. 
716 Armenta S, Moreno-Mendieta S, Sánchez-Cuapio Z, Sánchez S, Rodríguez-Sanoja R. 2017.

717 Advances in molecular engineering of carbohydrate-binding modules. Proteins: Structure,

718 Function and Bioinformatics 85:1602-1617. DOI: 10.1002/prot.25327.

719 Baroroh U, Yusuf M, Rachman SD, Ishmayana S, Syamsunarno MRAA, Levita J, Subroto T.

720 2017. The importance of surface-binding site towards starch-adsorptivity level in $\alpha$-amylase: A

721 review on structural point of view. Enzyme Research 2017:4086845. DOI:

$72210.1155 / 2017 / 4086845$.

723 Baroroh U, Yusuf M, Rachman SD, Ishmayana S, Hasan K, Subroto T. 2019. Molecular

724 dynamics study to improve the substrate adsorption of Saccharomycopsis fibuligera R64 alpha-

725 amylase by designing a new surface binding site. Advances and Applications in Bioinformatics

726 and Chemistry: AABC 12:1-13. DOI: 10.2147/AABC.S198110.

727 Božić N, Rozeboom HJ, Lončar N, Slavić MŠ, Janssen DB, Vujčić Z. 2020. Characterization of

728 the starch surface binding site on Bacillus paralicheniformis $\alpha$-amylase. International Journal of

729 Biological Macromolecules 165:1529-1539. DOI: 10.1016/j.ijbiomac.2020.10.025.

730 Brosnan MP, Kelly CT, Fogarty WM. 1992. Investigation of the mechanisms of irreversible

731 thermoinactivation of Bacillus stearothermophilus a-amylase. European Journal of Biochemistry

732 203:225-231. DOI: 10.1111/j.1432-1033.1992.tb19850.x.

733 Brzozowski AM, Lawson DM, Turkenburg JP, Bisgaard-Frantzen H, Svendsen A, Borchert T

734 V., Dauter Z, Wilson KS, Davies GJ. 2000. Structural analysis of a chimeric bacterial $\alpha-$

735 Amylase. High-resolution analysis of native and ligand complexes. Biochemistry 39:9099-9107.

736 DOI: 10.1021/bi0000317.

737 Campos BM, Liberato MV, Alvarez TM, Zanphorlin LM, Ematsu GC, Barud H, Polikarpov I,

738 Ruller R, Gilbert HJ, de Mattos Zeri AC, Squina FM. 2016. A novel carbohydrate-binding

739 module from sugar cane soil metagenome featuring unique structural and carbohydrate affinity

740 properties. Journal of Biological Chemistry 291:23734-23743. DOI: 10.1074/jbc.M116.744383.

741 Cao L, Chen R, Huang X, Li S, Zhang S, Yang X, Qin Z, Kong W, Xie W, Liu Y. 2020.

742 Engineering of $\beta$-glucosidase Bgl15 with simultaneously enhanced glucose tolerance and

743 thermostability to improve its performance in high-solid cellulose hydrolysis. Journal of

744 Agricultural and Food Chemistry 68:5391-5401. DOI: 10.1021/acs.jafc.0c01817.

745 Chi MC, Chen YH, Wu TJ, Lo HF, Lin LL. 2010. Engineering of a truncated $\alpha$-amylase of

746 Bacillus sp. strain TS-23 for the simultaneous improvement of thermal and oxidative stabilities.

747 Journal of Bioscience and Bioengineering 109:531-538. DOI: 10.1016/j.jbiosc.2009.11.012.

748 Cockburn DW, Suh C, Medina KP, Duvall RM, Wawrzak Z, Henrissat B, Koropatkin NM. 2018.

749 Novel carbohydrate binding modules in the surface anchored $\alpha$-amylase of Eubacterium rectale

750 provide a molecular rationale for the range of starches used by this organism in the human gut.

751 Molecular Microbiology 107:249-264. DOI: 10.1111/mmi.13881.

752 Contreras F, Pramanik S, Rozhkova AM, Zorov IN, Korotkova O, Sinitsyn AP, Schwaneberg U,

753 Davari MD. 2020. Engineering robust cellulases for tailored lignocellulosic degradation

754 cocktails. International Journal of Molecular Sciences 21:1589. DOI: 10.3390/ijms21051589.

755 Deng Z, Yang H, Li J, Shin HD, Du G, Liu L, Chen J. 2014. Structure-based engineering of

756 alkaline $\alpha$-amylase from alkaliphilic Alkalimonas amylolytica for improved thermostability.

757 Applied Microbiology and Biotechnology 98:3997-4007. DOI: 10.1007/s00253-013-5375-y.

758 Du R, Song Q, Zhang Q, Zhao F, Kim RC, Zhou Z, Han Y. 2018. Purification and

759 characterization of novel thermostable and Ca-independent $\alpha$-amylase produced by Bacillus

760 amyloliquefaciens BH072. International Journal of Biological Macromolecules 115:1151-1156.

761 DOI: 10.1016/j.ijbiomac.2018.05.004.

PeerJ reviewing PDF | (2021:02:58040:1:0:REVIEW 15 Mar 2021) 
762

763

764

765

766

767

768

769

770

771

772

773

774

775

776

777

778

779

780

781

782

783

784

785

786

787

788

789

790

791

792

793

794

795

796

797

798

799

800

801

802

803

804

805

El-Sayed AKA, Abou-Dobara MI, El-Fallal AA, Omar NF. 2019. Heterologous expression, purification, immobilization and characterization of recombinant $\alpha$-amylase AmyLa from Laceyella sp. DS3. International Journal of Biological Macromolecules 132:1274-1281. DOI: 10.1016/j.ijbiomac.2019.04.010.

Furukawa T, Sawaguchi C, Watanabe A, Takahashi M, Nigorikawa M, Furukawa K, Iimura Y, Kajita S, Oguchi T, Ito Y, Sonoki T. 2013. Application of fungal laccase fused with cellulosebinding domain to develop low-lignin rice plants. Journal of Bioscience and Bioengineering 116:616-619. DOI: 10.1016/j.jbiosc.2013.05.007.

Gai Y, Chen J, Zhang S, Zhu B, Zhang D. 2018. Property improvement of $\alpha$-amylase from Bacillus stearothermophilus by deletion of amino acid residues arginine 179 and glycine 180 . Food Technology and Biotechnology 56:58-64. DOI: 10.17113/ftb.56.01.18.5448.

Gandhi S, Salleh AB, Rahman RNZRA, Chor Leow T, Oslan SN. 2015. Expression and characterization of Geobacillus stearothermophilus SR74 recombinant $\alpha$-amylase in Pichia pastoris. BioMed Research International 2015:529059. DOI: 10.1155/2015/529059.

Hammami A, Fakhfakh N, Abdelhedi O, Nasri M, Bayoudh A. 2018. Proteolytic and amylolytic enzymes from a newly isolated Bacillus mojavensis SA: Characterization and applications as laundry detergent additive and in leather processing. International Journal of Biological Macromolecules 108:56-68. DOI: 10.1016/j.ijbiomac.2017.11.148.

Huang L, Shan M, Ma J, Li Y, Xu Z, Shao S, Wang X, Wang K, Xiao D, Lu F, Liu Y. 2019. Directed evolution of $\alpha$-amylase from Bacillus licheniformis to enhance its acid-stable performance. Biologia 74:1363-1372. DOI: 10.2478/s11756-019-00262-7.

Igarashi K, Hagihara H, Ito S. 2003. Protein engineering of detergent $\alpha$-amylases. Trends in Glycoscience and Glycotechnology 15:101-114. DOI: 10.4052/tigg.15.101.

Janeček Š, Mareček F, MacGregor EA, Svensson B. 2019. Starch-binding domains as CBM families-history, occurrence, structure, function and evolution. Biotechnology Advances 37:107451. DOI: 10.1016/j.biotechadv.2019.107451.

Ju L, Deng G, Liang J, Zhang H, Li Q, Pan Z, Yu M, Long H. 2019. Structural organization and functional divergence of high isoelectric point $\alpha$-amylase genes in bread wheat (Triticum aestivum L.) and barley (Hordeum vulgare L.) 06 Biological Sciences 0604 Genetics 07 Agricultural and Veterinary Sciences 0703 Crop and Pa. BMC Genetics 20:25. DOI: 10.1186/s12863-019-0732-1.

Kaneko A, Sudo S, Takayasu-Sakamoto Y, Tamura G, Ishikawa T, Oba T. 1996. Molecular cloning and determination of the nucleotide sequence of a gene encoding an acid-stable $\alpha$ amylase from Aspergillus kawachii. Journal of Fermentation and Bioengineering 81:292-298. DOI: 10.1016/0922-338X(96)80579-4.

Karimi M, Biria D. 2016. The synergetic effect of starch and alpha amylase on the biodegradation of n-alkanes. Chemosphere 152:166-172. DOI:

10.1016/j.chemosphere.2016.02.120.

Karimi M, Biria D. 2019. The promiscuous activity of alpha-amylase in biodegradation of lowdensity polyethylene in a polymer-starch blend. Scientific Reports 9:2612. DOI: 10.1038/s41598019-39366-0.

Keskin Ş, Ertunga NS. 2017. Purification, immobilization and characterization of thermostable $\alpha$-amylase from a thermophilic bacterium Geobacillus sp. TF14. Turkish Journal of Biochemistry 42:633-642. DOI: 10.1515/tjb-2016-0123.

PeerJ reviewing PDF | (2021:02:58040:1:0:REVIEW 15 Mar 2021) 
806 Khemakhem B, Ali M Ben, Aghajari N, Juy M, Haser R, Bejar S. 2009. Engineering of the $\alpha$ 807 amylase from Geobacillus stearothermophilus US100 for detergent incorporation. Biotechnology 808 and Bioengineering 102:380-389. DOI: 10.1002/bit.22083.

809 Kimple ME, Brill AL, Pasker RL. 2013. Overview of affinity tags for protein purification.

810 Current Protocols in Protein Science 73:9.9.1-9.9.23. DOI: 10.1002/0471140864.ps0909s73.

811 Koshland DE. 1953. Stereochemistry and the mechanism of enzymatic reactions. Biological

812 Reviews 28:416-436. DOI: 10.1111/j.1469-185X.1953.tb01386.x.Li C, Du M, Cheng B, Wang

813 L, Liu X, Ma C, Yang C, Xu P. 2014. Close relationship of a novel Flavobacteriaceae $\alpha$-amylase

814 with archaeal $\alpha$-amylases and good potentials for industrial applications. Biotechnology for

815 Biofuels 7:18. DOI: 10.1186/1754-6834-7-18.

816 Li Z, Duan X, Chen S, Wu J. 2017. Improving the reversibility of thermal denaturation and 817 catalytic efficiency of Bacillus licheniformis $\alpha$-amylase through stabilizing a long loop in domain 818 B. PLoS ONE 12:e0173187. DOI: 10.1371/journal.pone.0173187.

819 Li Z, Duan X, Wu J. 2016. Improving the thermostability and enhancing the $\mathrm{Ca}^{2+}$ binding of the 820 maltohexaose-forming $\alpha$-amylase from Bacillus stearothermophilus. Journal of Biotechnology 821 222:65-72. DOI: 10.1016/j.jbiotec.2016.02.013.

822 Li S, Yang Q, Tang B. 2020. Improving the thermostability and acid resistance of Rhizopus 823 oryzae $\alpha$-amylase by using multiple sequence alignment based site-directed mutagenesis.

824 Biotechnology and Applied Biochemistry 67:677-684. DOI: 10.1002/bab.1907.

825 Li S, Yang Q, Tang B, Chen A. 2018. Improvement of enzymatic properties of Rhizopus oryzae $826 \alpha$-amylase by site-saturation mutagenesis of histidine 286. Enzyme and Microbial Technology

827 117:96-102. DOI: 10.1016/j.enzmictec.2018.06.012.

828 Lim SJ, Muhd Noor ND, Salleh AB, Oslan SN. 2020. Structure prediction of a thermostable 829 SR74 $\alpha$-amylase from Geobacillus stearothermophilus expressed in CTG-clade yeast 830 Meyerozyma guilliermondii strain SO. Catalysts 10:1059.

831 Lim SJ, Oslan SNH, Oslan SN. 2020. Purification and characterisation of thermostable $\alpha-$ 832 amylases from microbial sources. BioResources 15:2005-2029. DOI:

833 10.15376/biores.15.1.2005-2029.

834 Lin LL, Lo HF, Chiang WY, Hu HY, Hsu WH, Chang CT. 2003. Replacement of methionine 835208 in a truncated Bacillus sp. TS-23 $\alpha$-amylase with oxidation-resistant leucine enhances its 836 resistance to hydrogen peroxide. Current Microbiology 46:211-216. DOI: 10.1007/s00284-002837 3846-y.

838 Liu Y, Huang L, Jia L, Gui S, Fu Y, Zheng D, Guo W, Lu F. 2017. Improvement of the acid 839 stability of Bacillus licheniformis alpha amylase by site-directed mutagenesis. Process 840 Biochemistry 58:174-180. DOI: 10.1016/j.procbio.2017.04.040.

841 Lombard V, Golaconda Ramulu H, Drula E, Coutinho PM, Henrissat B. 2014. The carbohydrate842 active enzymes database (CAZy) in 2013. Nucleic Acids Research 42:D490-D495. DOI: 843 10.1093/nar/gkt1178.

844 McCarter JD, Stephen Withers G. 1994. Mechanisms of enzymatic glycoside hydrolysis. Current 845 Opinion in Structural Biology 4:885-892. DOI: 10.1016/0959-440X(94)90271-2.

846 Mehta D, Satyanarayana T. 2014. Domain C of thermostable $\alpha$-amylase of Geobacillus 847 thermoleovorans mediates raw starch adsorption. Applied Microbiology and Biotechnology 848 98:4503-4519. DOI: 10.1007/s00253-013-5459-8.

849 Mehta D, Satyanarayana T. 2016. Bacterial and archaeal $\alpha$-amylases: Diversity and amelioration 850 of the desirable characteristics for industrial applications. Frontiers in Microbiology 7:1129.

851 DOI: 10.3389/fmicb.2016.01129. 
852 Meruvu H. 2019. Polyextremotolerant amylase produced from novel Enterococcus with

853 potpourri of applications. International Journal of Peptide Research and Therapeutics 25:1669-

854 1678. DOI: 10.1007/s10989-019-09809-3.

855 Nagashima T, Tada S, Kitamoto K, Gomi K, Kumagai C, Toda H. 1992. Site-directed

856 mutagenesis of catalytic active-site residues of Taka-amyiase A. Bioscience, Biotechnology, and

857 Biochemistry 56:207-210. DOI: 10.1271/bbb.56.207.

858 Nasir NSM, Leow CT, Oslan SNH, Salleh AB, Oslan SN. 2020. Molecular expression of a 859 recombinant thermostable bacterial amylase from Geobacillus stearothermophilus SR74 using 860 methanol-free Meyerozyma guilliermondii strain SO yeast system. BioResources 15:3161-3172.

861 Natalia D, Vidilaseris K, Ismaya WT, Puspasari F, Prawira I, Hasan K, Fibriansah G, Permentier

862 HP, Nurachman Z, Subroto T, Dijkstra BW, Soemitro S. 2015. Effect of introducing a disulphide 863 bond between the A and C domains on the activity and stability of Saccharomycopsis fibuligera 864 R64 a-amylase. Journal of Biotechnology 195:8-14. DOI: 10.1016/j.jbiotec.2014.12.002.

865 Nigam PS. 2013. Microbial enzymes with special characteristics for biotechnological

866 applications. Biomolecules 3:597-611. DOI: 10.3390/biom3030597.

867 Offen WA, Viksoe-Nielsen A, Borchert T V., Wilson KS, Davies GJ. 2015. Three-dimensional

868 structure of a variant "Termamyl-like" Geobacillus stearothermophilus $\alpha$-amylase at $1.9 \AA$

869 resolution. Acta Crystallographica Section F:Structural Biology Communications F71:66-70.

870 DOI: 10.1107/S2053230X14026508.

871 Ozturk H, Ece S, Gundeger E, Evran S. 2013. Site-directed mutagenesis of methionine residues

872 for improving the oxidative stability of $\alpha$-amylase from Thermotoga maritima. Journal of

873 Bioscience and Bioengineering 116:449-451. DOI: 10.1016/j.jbiosc.2013.04.018.

874 Pan S, Ding N, Ren J, Gu Z, Li C, Hong Y, Cheng L, Holler TP, Li Z. 2017.

875 Maltooligosaccharide-forming amylase: Characteristics, preparation, and application.

876 Biotechnology Advances 35:619-632. DOI: 10.1016/j.biotechadv.2017.04.004.

877 Parashar D, Satyanarayana T. 2016. A chimeric $\alpha$-amylase engineered from Bacillus acidicola

878 and Geobacillus thermoleovorans with improved thermostability and catalytic efficiency.

879 Journal of Industrial Microbiology and Biotechnology 43:473-484. DOI: 10.1007/s10295-015-

$880 \quad 1721-7$.

881 Parashar D, Satyanarayana T. 2017. Production of chimeric acidic $\alpha$-amylase by the recombinant

882 Pichia pastoris and its applications. Frontiers in Microbiology 8:493. DOI:

883 10.3389/fmicb.2017.00493.

884 Priyadarshini S, Pradhan SK, Ray P. 2020. Production, characterization and application of

885 thermostable, alkaline $\alpha$-amylase (AA11) from Bacillus cereus strain SP-CH11 isolated from

886 Chilika Lake. International Journal of Biological Macromolecules 145:804-812. DOI:

887 10.1016/j.ijbiomac.2019.11.149.

888 Priyadarshini S, Ray P. 2019. Exploration of detergent-stable alkaline $\alpha$-amylase AA7 from

889 Bacillus sp. strain SP-CH7 isolated from Chilika Lake. International Journal of Biological

890 Macromolecules 140:825-832. DOI: 10.1016/j.ijbiomac.2019.08.006.

891 Robinson PK. 2015. Enzymes: principles and biotechnological applications. Essays in

892 Biochemistry 59:1-41. DOI: 10.1042/BSE0590001.

893 Sadhasivam B, Thanaraj P, Veerichetty V, Nachimuthu S, Ponnusamy R, Peraman M, 894 Jabamalairaj H, Ramachandran SD. 2018. Production and application of $\alpha$-amylase from

895 indigenous fungal strain Aspergillus luchuensis bs1. Malaysian Journal of Microbiology 14:215-

896 228. DOI: $10.21161 / \mathrm{mjm} .107117$. 
897 Sharma A, Gupta G, Ahmad T, Mansoor S, Kaur B. 2019. Enzyme Engineering: Current Trends 898 and Future Perspectives. Food Reviews International. DOI: 10.1080/87559129.2019.1695835. 899 Shruthi BR, Achur RNH, Nayaka Boramuthi T. 2020. Optimized solid-state fermentation 900 medium enhances the multienzymes production from Penicillium citrinum and Aspergillus 901 clavatus. Current Microbiology 77:2192-2206. DOI: 10.1007/s00284-020-02036-w.

902 Sidar A, Albuquerque ED, Voshol GP, Ram AFJ, Vijgenboom E, Punt PJ. 2020. Carbohydrate 903 binding modules: Diversity of domain architecture in amylases and cellulases from filamentous 904 microorganisms. Frontiers in Bioengineering and Biotechnology 8:871. DOI:

905 10.3389/fbioe.2020.00871.

906 Singhvi P, Saneja A, Srichandan S, Panda AK. 2020. Bacterial inclusion bodies: A treasure trove 907 of bioactive proteins. Trends in Biotechnology 38:474-486. DOI: 10.1016/j.tibtech.2019.12.011. 908 Sobieraj AM, Huemer M, Zinsli L V., Meile S, Keller AP, Röhrig C, Eichenseher F, Shen Y, 909 Zinkernagel AS, Loessner MJ, Schmelcher M. 2020. Engineering of long-circulating 910 911 infection. mBio 11:e01781-20. DOI: 10.1128/mBio.01781-20.

Sudan SK, Kumar N, Kaur I, Sahni G. 2018. Production, purification and characterization of raw starch hydrolyzing thermostable acidic $\alpha$-amylase from hot springs, India. International Journal of Biological Macromolecules 117:831-839. DOI: 10.1016/j.ijbiomac.2018.05.231. Sulong MR, Leow TC, Noor R, Raja Z, Rahman A. 2015. Enhancing thermostability of maltogenic amylase from Geobacillus sp . SK70 by single amino acid substitution. International Journal of New Technologies in Science and Engineering 2:20-41.

Sun Y, Duan X, Wang L, Wu J. 2016. Enhanced maltose production through mutagenesis of acceptor binding subsite +2 in Bacillus stearothermophilus maltogenic amylase. Journal of Biotechnology 217:53-61. DOI: 10.1016/j.jbiotec.2015.11.007.

Svensson B. 1994. Protein engineering in the $\alpha$-amylase family: catalytic mechanism, substrate specificity, and stability. Plant Molecular Biology 25:141-157. DOI: 10.1007/BF00023233. Tan T-C, Mijts BN, Swaminathan K, Patel BKC, Divne C. 2008. Crystal structure of the polyextremophilic $\alpha$-amylase AmyB from Halothermothrix orenii: Details of a productive enzyme-substrate complex and an $\mathrm{N}$ domain with a role in binding raw starch. Journal of Molecular Biology 378:852-870. DOI: 10.1016/j.jmb.2008.02.041.

Trabelsi S, Ben Mabrouk S, Kriaa M, Ameri R, Sahnoun M, Mezghani M, Bejar S. 2019a. The optimized production, purification, characterization, and application in the bread making industry of three acid-stable alpha-amylases isoforms from a new isolated Bacillus subtilis strain US586. Journal of Food Biochemistry 43:e12826. DOI: 10.1111/jfbc.12826.

Trabelsi S, Sahnoun M, Elgharbi F, Ameri R, Ben Mabrouk S, Mezghani M, Hmida-Sayari A, Bejar S. 2019b. Aspergillus oryzae S2 AmyA amylase expression in Pichia pastoris: production, purification and novel properties. Molecular Biology Reports 46:921-932. DOI:

10.1007/s1 1033-018-4548-2.

Uzun U, Demirci E, Akatin MY. 2018. Purification and characterization of Rhizoctonia solani AG-4 strain ZB-34 $\alpha$-amylase produced by solid-state fermentation using corn bran. Turkish Journal of Biochemistry 43:257-267. DOI: 10.1515/tjb-2017-0159.

Vieira Gomes A, Souza Carmo T, Silva Carvalho L, Mendonça Bahia F, Parachin N. 2018. Comparison of yeasts as hosts for recombinant protein production. Microorganisms 6. DOI: 10.3390/microorganisms6020038. 
941 Vujičić-Žagar A, Dijkstra BW. 2006. Monoclinic crystal form of Aspergillus niger $\alpha$-amylase in 942 complex with maltose at $1.8 \AA$ resolution. Acta Crystallographica Section F 62:716-721. DOI:

$94310.1107 / \mathrm{S} 1744309106024729$.

944 Wang X, Kan G, Ren X, Yu G, Shi C, Xie Q, Wen H, Betenbaugh M. 2018a. Molecular Cloning 945 and characterization of a novel $\alpha$-amylase from antarctic sea ice bacterium Pseudoalteromonas

946 sp. M175 and its primary application in detergent. BioMed Research International

947 2018:3258383. DOI: 10.1155/2018/3258383.

948 Wang CH, Liu XL, Huang RB, He BF, Zhao MM. 2018b. Enhanced acidic adaptation of

949 Bacillus subtilis Ca-independent alpha-amylase by rational engineering of $\mathrm{pKa}$ values.

950 Biochemical Engineering Journal 139:146-153. DOI: 10.1016/j.bej.2018.08.015.

951 Wang CH, Lu LH, Huang C, He BF, Huang RB. 2020. Simultaneously improved thermostability 952 and hydrolytic pattern of alpha-amylase by engineering central beta strands of TIM barrel.

953 Applied Biochemistry and Biotechnology 192:57-70. DOI: 10.1007/s12010-020-03308-8.

954 Wang YC, Zhao N, Ma JW, Liu J, Yan QJ, Jiang ZQ. 2019. High-level expression of a novel $\alpha-$ 955 amylase from Thermomyces dupontii in Pichia pastoris and its application in maltose syrup 956 production. International Journal of Biological Macromolecules 127:683-692. DOI:

957 10.1016/j.ijbiomac.2019.01.162.

958 Xian L, Wang F, Luo X, Feng YL, Feng JX. 2015. Purification and characterization of a highly 959 efficient calcium-independent $\alpha$-amylase from Talaromyces pinophilus 1-95. PLoS ONE 10:1960 18. DOI: 10.1371/journal.pone.0121531.

961 Xie X, Ban X, Gu Z, Li C, Hong Y, Cheng L, Li Z. 2020. Structure-based engineering of a 962 maltooligosaccharide-forming amylase to enhance product specificity. Journal of Agricultural 963 and Food Chemistry 68:838-844. DOI: 10.1021/acs.jafc.9b07234.

964 Xie X, Li Y, Ban X, Zhang Z, Gu Z, Li C, Hong Y, Cheng L, Jin T, Li Z. 2019a. Crystal 965 structure of a maltooligosaccharide-forming amylase from Bacillus stearothermophilus STB04.

966 International Journal of Biological Macromolecules 138:394-402. DOI:

967 10.1016/j.ijbiomac.2019.07.104.

968 Xie X, Qiu G, Zhang Z, Ban X, Gu Z, Li C, Hong Y, Cheng L, Li Z. 2019b. Importance of 969 Trp139 in the product specificity of a maltooligosaccharide-forming amylase from Bacillus 970 stearothermophilus STB04. Applied Microbiology and Biotechnology 103:9433-9442. DOI: 971 10.1007/s00253-019-10194-6.

972 Yang G, Yao H, Mozzicafreddo M, Ballarini P, Pucciarelli S, Miceli C. 2017. Rational 973 engineering of a cold-adapted $\alpha$-amylase from the Antarctic ciliate Euplotes focardii for 974 simultaneous improvement of thermostability and catalytic activity. Applied and Environmental 975 Microbiology 83. DOI: 10.1128/AEM.00449-17.

976 Yang H, Liu L, Shin HD, Li J, Du G, Chen J. 2013a. Structure-guided systems-level engineering 977 of oxidation-prone methionine residues in catalytic domain of an alkaline $\alpha$-amylase from 978 Alkalimonas amylolytica for significant improvement of both oxidative stability and catalytic 979 efficiency. PLoS ONE 8:e57403. DOI: 10.1371/journal.pone.0057403.

980 Yang H, Liu L, Wang M, Li J, Wang NS, Du G, Chen J. 2012. Structure-based engineering of 981 methionine residues in the catalytic cores of alkaline amylase from Alkalimonas amylolytica for 982 improved oxidative stability. Applied and Environmental Microbiology 78:7519-7526. DOI: 983 10.1128/AEM.01307-12.

984 Yang H, Lu X, Liu L, Li J, Shin HD, Chen RR, Du G, Chen J. 2013b. Fusion of an oligopeptide 985 to the $\mathrm{N}$ terminus of an alkaline $\alpha$-amylase from Alkalimonas amylolytica simultaneously 
986 improves the enzyme's catalytic efficiency, thermal stability, and resistance to oxidation. Applied 987 and Environmental Microbiology 79:3049-3058. DOI: 10.1128/AEM.03785-12.

988 Yi Z, Fang Y, He K, Liu D, Luo H, Zhao D, He H, Jin Y, Zhao H. 2018. Directly mining a 989 fungal thermostable $\alpha$-amylase from Chinese Nong-flavor liquor starter. Microbial Cell 990 Factories 17:30. DOI: 10.1186/s12934-018-0878-y.

991 Yin H, Yang Z, Nie X, Li S, Sun X, Gao C, Wang Z, Zhou G, Xu P, Yang C. 2017. Functional 992 and cooperative stabilization of a two-metal $(\mathrm{Ca}, \mathrm{Zn})$ center in $\alpha$-amylase derived from 993 Flavobacteriaceae species. Scientific Reports 7:17933. DOI: 10.1038/s41598-017-18085-4. 994 Yusuf M, Baroroh U, Hasan K, Rachman SD, Ishmayana S, Subroto T. 2017. Computational 995 model of the effect of a surface-binding site on the Saccharomycopsis fibuligera R64 $\alpha$-amylase to the substrate adsorption. Bioinformatics and Biology Insights 11:1177932217738764. DOI: $10.1177 / 1177932217738764$. Zechel DL, Withers SG. 2000. Glycosidase mechanisms: Anatomy of a finely tuned catalyst. Accounts of chemical research 33:11-18. DOI: 10.1021/ar970172+. Zechel DL, Withers SG. 2001. Dissection of nucleophilic and acid-base catalysis in glycosidases. Current Opinion in Chemical Biology 5:643-649. DOI: 10.1016/S13675931(01)00260-5. T, Luo H. 2017. Improving the catalytic performance of a Talaromyces leycettanus $\alpha$-amylase by changing the linker length. Journal of Agricultural and Food Chemistry 65:5041-5048. DOI: 10.1021/acs.jafc.7b00838. Zhang R, Yip VLY, Withers SG. 2010. 8.11 - Mechanisms of enzymatic glycosyl transfer. In: Liu H-W (Ben), Mander L eds. Comprehensive Natural Products II. Oxford: Elsevier, 385-422. DOI: 10.1016/B978-008045382-8.00167-2. 
Figure 1

Reaction mechanisms of amylases.

(A) $\alpha$-Retaining double displacement mechanism of $\alpha$-amylases. (B) Inverting single displacement mechanism of $\beta$-amylases. The figure was adapted from Zhang et al., 2010 and all the chemical structures were redrawn using ChemDraw ${ }^{\circledR}$ JS version 19.

(A)

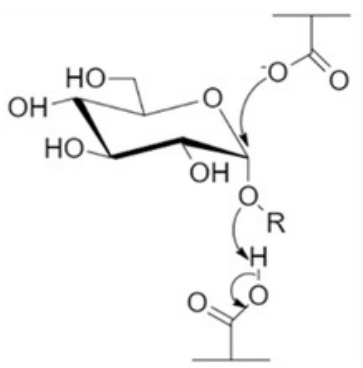

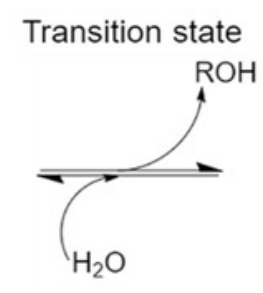

Glycosylation

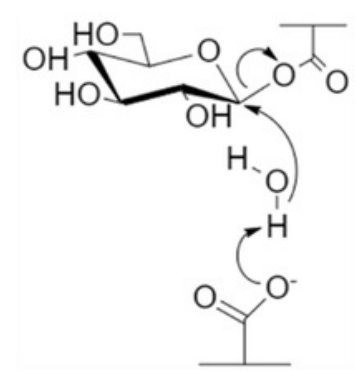

Deglycosylation

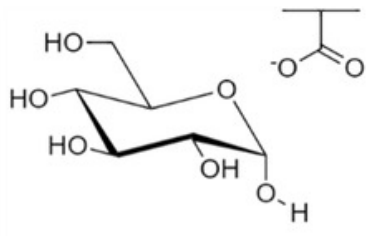

O

(B)
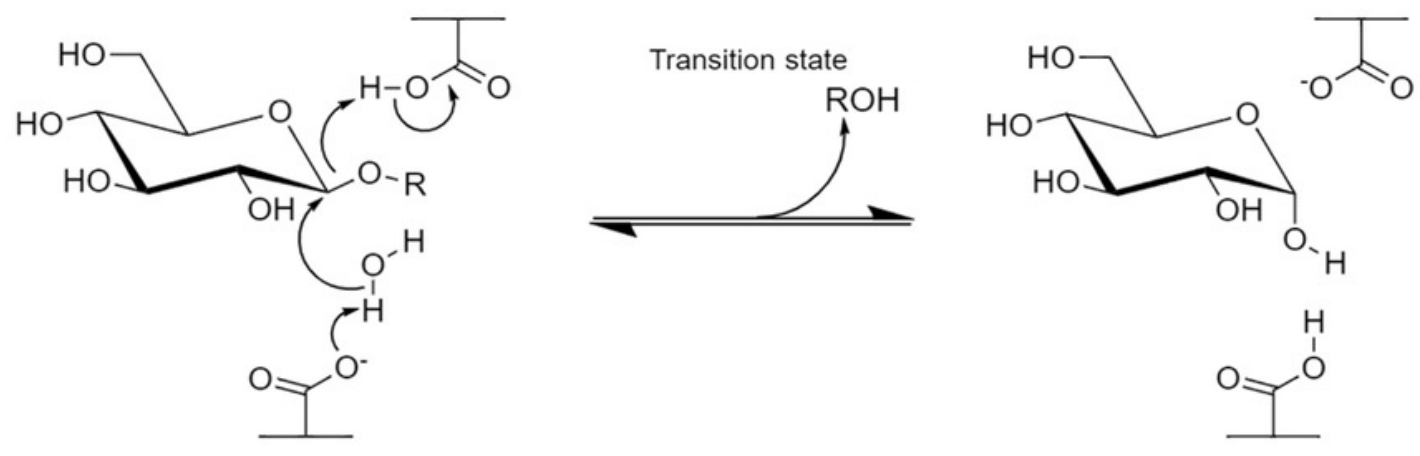


\section{Figure 2}

3D crystal structure of $B$. paralicheniformis $\alpha$-amylase (BliAmy; PDB ID: 6TP1) with maltotetraose at its substrate-binding site (SBS) (Božić et al., 2020).

(A) BliAmy has a three-domain fold structure which is composed of Domain A, Domain B and Domain $\mathrm{C}$ as depicted in light blue, violet and wheat colours, respectively. The catalytic triad residues (D231, E264 and D328) are shown as orange sticks while the calcium and sodium ions are depicted as blue and red balls, respectively. (B) The SBS in BliAmy consists of two hydrophobic residues (F257 and Y358) in cyan colour where the yellow dashed line between the residues is the $\pi-\pi$ hydrophobic interaction at $5 \AA$. Maltotetraose (MTT) molecule is shown as green carbon backbone. The structural image was generated using the PyMOL Molecular Graphic System, Version 2.4 Schrödinger, LLC.

(A)

(B)

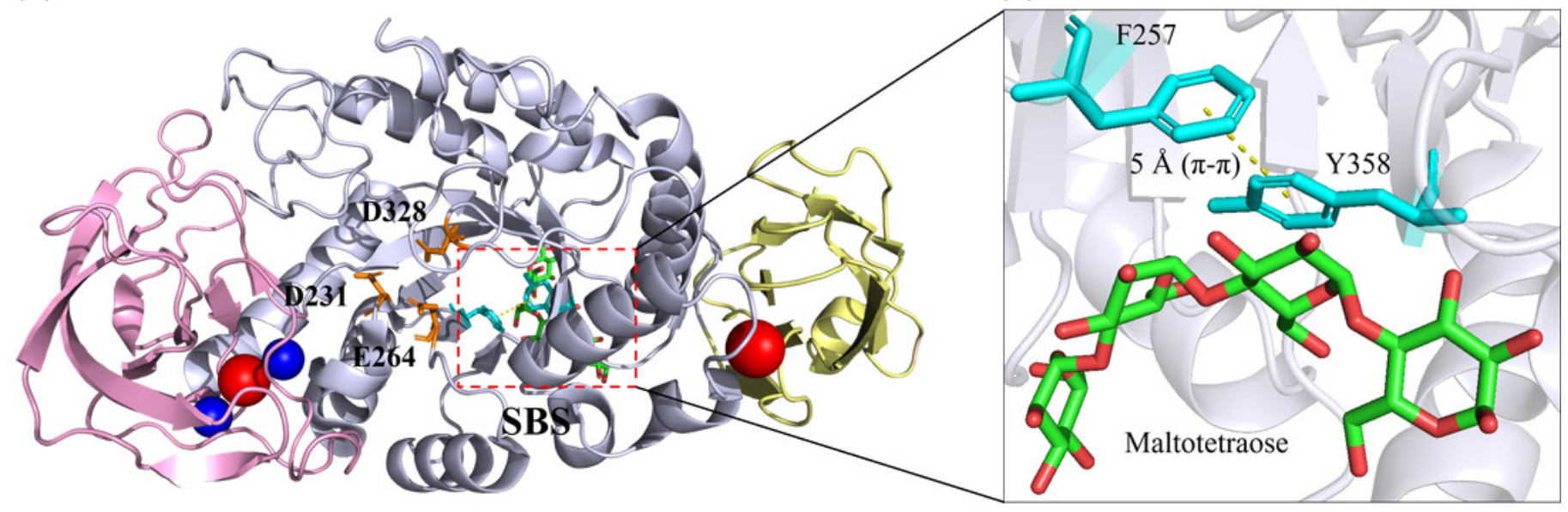


Figure 3

Site-directed mutagenesis of G109D in Bst-MfAse (PDB ID: 6ag0; Xie et al., 2019a).

Extra interaction at subsite - 6 has been established with the introduction of D109 compared to the wild type (G109), leading to the highest increment of the G6 production from starch at $42.4 \%$ compared to other mutants (G109N and G109F) compared to its wild type (G109) (Xie et al., 2020). The structural figures were illustrated using the PyMOL Molecular Graphic System, Version 2.4 Schrödinger, LLC.

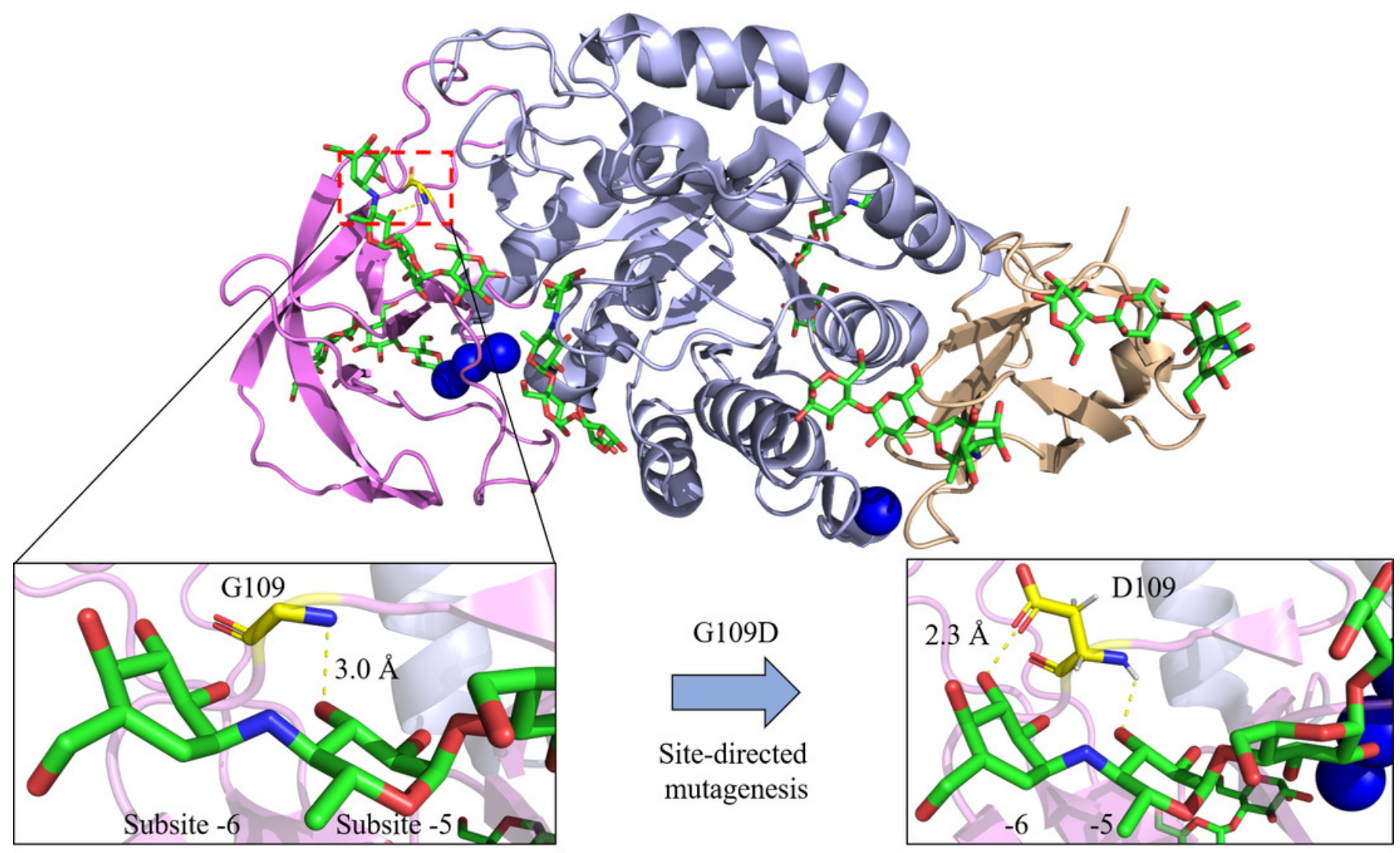




\section{Table 1 (on next page)}

Characterization of microbial $\alpha$-amylases and their desired traits for industrial applications. 
Table 1 Characterization of microbial $\alpha$-amylases and their desired traits for industrial applications.

\begin{tabular}{|c|c|c|c|}
\hline Sources of $\alpha$-amylases & $\begin{array}{l}\text { Optimum temperature and } \\
\mathrm{pH}\end{array}$ & Desired traits and performance & References \\
\hline \multicolumn{4}{|c|}{ Starch Saccharification and Liquefaction } \\
\hline $\begin{array}{l}\text { Bacillus amyloliquefaciens } \\
\mathrm{BH} 072\end{array}$ & $60^{\circ} \mathrm{C}, \mathrm{pH} 7.0$ & $\begin{array}{l}\text { Hydrolyzed } 57.52 \%, 49.61 \% \text {, and } 32.35 \% \text { of } \\
1 \%(w / v) \text { corn, wheat and potato starches, } \\
\text { respectively }\end{array}$ & (Du et al., 2018) \\
\hline Geobacillus sp. K1C & $80^{\circ} \mathrm{C}, \mathrm{pH} 6.0$ & $\begin{array}{l}\text { Degraded } 88.1 \%, 90.3 \% \text {, and } 81.1 \% \text { of } 10 \% \\
(w / v) \text { rice, wheat, and potato starches, } \\
\text { respectively }\end{array}$ & (Sudan et al., 2018) \\
\hline \multicolumn{4}{|l|}{ Baking } \\
\hline Bacillus subtilis strain US586 & $60^{\circ} \mathrm{C}, \mathrm{pH} 4.0-6.0$ & $\begin{array}{l}\text { Decreased elasticity : extensibility ratio to } \\
1.2 \text {; increased dough baking strength to } 172 \times \\
10^{-4} \mathrm{~J}\end{array}$ & $\begin{array}{l}\text { (Trabelsi et al., } \\
\text { 2019a) }\end{array}$ \\
\hline $\begin{array}{l}\text { Laceyella sp. DS3 (expressed } \\
\text { in Escherichia coli BL21) }\end{array}$ & $\begin{array}{l}55^{\circ} \mathrm{C} \text { (intermediate } \\
\text { temperature stable, ITS), } \\
\mathrm{pH} 6.0-7.0\end{array}$ & Not stated & $\begin{array}{l}\text { (El-Sayed et al., } \\
\text { 2019) }\end{array}$ \\
\hline \multicolumn{4}{|l|}{ Beverages } \\
\hline $\begin{array}{l}\text { Thermomyces dupontii } \\
\text { (expressed in Komagataella } \\
\text { phaffii) }\end{array}$ & $60{ }^{\circ} \mathrm{C}, \mathrm{pH} 6.5$ & $\begin{array}{l}52 \% \text { liquefied starch to maltose conversion at } \\
8 \mathrm{~h}\end{array}$ & (Wang et al., 2019) \\
\hline $\begin{array}{l}\text { Rhizactonia solani AG-4 strain } \\
\text { ZB-34 }\end{array}$ & $50{ }^{\circ} \mathrm{C}, \mathrm{pH} 5.5$ & $\begin{array}{l}\text { Reduced colour intensity of raw apple juice } \\
\left(\mathrm{OD}_{440 \mathrm{~nm}}\right) \text { up to } 71.2 \% \text { at } 3 \mathrm{~h}\end{array}$ & $\begin{array}{l}\text { (Uzun, Demirci \& } \\
\text { Akatin, 2018) }\end{array}$ \\
\hline $\begin{array}{l}\text { Fungus (expressed in } K \\
\text { phaffii) }\end{array}$ & $60{ }^{\circ} \mathrm{C}, \mathrm{pH} 5.0-5.5$ & $\begin{array}{l}\text { Maximum specific activity ( } 200.4 \mathrm{U} / \mathrm{mg} \text { ) on } \\
\text { amylopectin which is abundantly found in } \\
\text { wheat material }\end{array}$ & (Yi et al., 2018) \\
\hline \multicolumn{4}{|l|}{ Detergent } \\
\hline Bacillus mojavensis SA & $55^{\circ} \mathrm{C}, \mathrm{pH} 9.0$ & $\begin{array}{l}\text { Retained }>34 \% \text { activity in } 1 \% \text { non-ionic and } \\
\text { anionic surfactants as well as oxidizing } \\
\text { agents }\end{array}$ & $\begin{array}{l}\text { (Hammami et al., } \\
\text { 2018) }\end{array}$ \\
\hline Bacillus sp. SP-CH7 & $65^{\circ} \mathrm{C}, \mathrm{pH} 9.0$ & Retained $>95 \%$ starch stain removal rate & (Priyadarshini \& \\
\hline
\end{tabular}


with detergent added

Retained $>76.9 \%$ amylolytic activity towards tested laundry detergents with better wash performance as a detergent additive

\section{Textile and Leather}

Aspergillus luchuensis BS1

$60{ }^{\circ} \mathrm{C}, \mathrm{pH} 5.5$

Biodegradation

B. subtilis TB1

$25^{\circ} \mathrm{C}, \mathrm{pH} 8.0$

Desized cotton fabric with $9.5 \%$ weight loss, $5 \mathrm{~s}$ of absorbency time and 8 rating in Tegewa analysis
Increased biodegradation efficiency (53\%) of (Karimi \& Biria, residual hydrocarbons in the presence of starch

Reduced weight (48\%) and tensile strength (87\%) of low-density polyethylene (LDPE)starch blend samples
Ray, 2019)

(Wang et al., 2018a)

(Sadhasivam et al., 2018) 2016)

(Karimi \& Biria, 2019) 


\section{Table 2 (on next page)}

Engineering of microbial $\alpha$-amylases for enhanced thermostability, $\mathrm{pH}$ tolerance, substrate and product specificities as well as oxidative stability. 
Table 2 Engineering of microbial $\alpha$-amylases for enhanced thermostability, $\mathrm{pH}$ tolerance, substrate and product specificities as well as oxidative stability.

\begin{tabular}{|c|c|c|c|}
\hline Microbial strains & Modifications & Improvements & References \\
\hline \multicolumn{4}{|l|}{ Thermostability } \\
\hline B. subtilis CN7 & V260I & $\begin{array}{l}\text { Increased melting point }\left(7.1^{\circ} \mathrm{C}\right) \text { and } \\
\text { half-inactivation temperatures }\left(4.9^{\circ} \mathrm{C}\right)\end{array}$ & (Wang et al., 2020) \\
\hline B. stearothermophilus & $\Delta \mathrm{R} 179-\mathrm{G} 180$ & $\begin{array}{l}\text { Increased half-life at } 100{ }^{\circ} \mathrm{C}(24 \text { to } 33 \\
\text { min) }\end{array}$ & (Gai et al., 2018) \\
\hline $\begin{array}{l}\text { Flavobacteriaceae } \\
\text { sinomicrobium }\end{array}$ & E200C, H201C & $\begin{array}{l}\text { Increased ligand-dependent } \\
\text { thermostability at } 50^{\circ} \mathrm{C} \text { for } 30 \mathrm{~min}\end{array}$ & (Yin et al., 2017) \\
\hline B. licheniformis & S187D, N188T, A269K & Increased half-life (9-fold) at $95^{\circ} \mathrm{C}$ & (Li et al., 2017) \\
\hline B. stearothermophilus & $\Delta \mathrm{I} 181-\mathrm{G} 182, \mathrm{~N} 193 \mathrm{~F}$ & $\begin{array}{l}\text { Increased half-life at } 95^{\circ} \mathrm{C} \text { at } 26 \text {-fold } \\
\left(\mathrm{Ca}^{2+} \text {-absent }\right) \text { and } 5 \text {-fold }\left(\mathrm{Ca}^{2+} \text {-present }\right)\end{array}$ & $\begin{array}{l}\text { (Li, Duan \& Wu, } \\
\text { 2016) }\end{array}$ \\
\hline $\begin{array}{l}\text { B. acidicola }(\mathrm{Ba}), G . \\
\text { thermoleovorans }(\mathrm{Gt})\end{array}$ & Chimeric Ba-Gt & $\begin{array}{l}\text { Increased half-life at } 90^{\circ} \mathrm{C} \text { ( } 5 \text { to } 15 \\
\text { min) }\end{array}$ & $\begin{array}{l}\text { (Parashar \& } \\
\text { Satyanarayana, } \\
\text { 2016) }\end{array}$ \\
\hline $\begin{array}{l}\text { Saccharomyces fibuligera } \\
\text { R64 }\end{array}$ & $\mathrm{S} 336 \mathrm{C}, \mathrm{S} 437 \mathrm{C}$ & Maintained $60 \%$ activity at $65^{\circ} \mathrm{C}$ & (Natalia et al., 2015) \\
\hline Geobacillus sp. SK70 & Q294H & $\begin{array}{l}\text { Increased optimum temperature ( } 55 \text { to } \\
60{ }^{\circ} \mathrm{C} \text { ) and thermostability ( } 35 \text { to } 85 \\
\text { min) }\end{array}$ & (Sulong et al., 2015) \\
\hline F. sinomicrobium & $\mathrm{K} 415 \mathrm{C}, \mathrm{S} 450 \mathrm{C}$ & $\begin{array}{l}\text { Increased half-life at } 50{ }^{\circ} \mathrm{C}(25 \text { to } 55 \\
\min ) \text {; maintained }>50 \% \text { activity at } 100 \\
{ }^{\circ} \mathrm{C}\end{array}$ & (Li et al., 2014) \\
\hline E. focardii & $\begin{array}{l}\text { E166P, S185P, V212T, V232T, } \\
\text { T350P }\end{array}$ & $\begin{array}{l}\text { Increased optimum temperature }(25 \text { to } \\
\left.30{ }^{\circ} \mathrm{C}\right) \text { and thermostability at } 50{ }^{\circ} \mathrm{C} \\
(1.8 \text { to } 3.3 \mathrm{~min})\end{array}$ & (Yang et al., 2017) \\
\hline \multicolumn{4}{|l|}{ pH tolerance and stability } \\
\hline Rhizopus oryzae & V174R & Increased half-life (2.55-fold) at $\mathrm{pH} 4.5$ & $\begin{array}{l}\text { (Li, Yang \& Tang, } \\
2020)\end{array}$ \\
\hline B. licheniformis & G81R & $\begin{array}{l}\text { Maintained } 10 \% \text { activity at } \mathrm{pH} 4.5 \text { for } \\
40 \text { min }\end{array}$ & (Huang et al., 2019) \\
\hline B. subtilis & $\mathrm{A} 270 \mathrm{~K}, \mathrm{~N} 271 \mathrm{H}$ & Decreased in optimum $\mathrm{pH}(\mathrm{pH} 6.5$ to & (Wang et al., 2018) \\
\hline
\end{tabular}




\begin{tabular}{|c|c|c|c|}
\hline & & $\begin{array}{l}\text { 4.5); maintained }>75 \% \text { activity at } \mathrm{pH} \\
3.5\end{array}$ & \\
\hline B. stearothermophilus & $\Delta \mathrm{R} 179-\mathrm{G} 180$ & $\begin{array}{l}\text { Increased acid-resistance in range of } \\
\mathrm{pH} 4.5-6.0 \text {; decreased optimum } \mathrm{pH} \\
\text { (pH 5.5) }\end{array}$ & (Gai et al., 2018) \\
\hline Rhizopus oryzae & $\mathrm{H} 286 \mathrm{E}$ & $\begin{array}{l}\text { Increased half-life }(6.43 \text {-fold }) \text { at } \mathrm{pH} 4.5 \\
(57.28 \text { to } 66.65 \mathrm{~min}) \text {; decrease } \\
\text { optimum } \mathrm{pH}(\mathrm{pH} 4.5)\end{array}$ & (Li et al., 2018) \\
\hline B. licheniformis & H293R, H316R, H327R & $\begin{array}{l}\text { Maintained } 31 \% \text { activity at } \mathrm{pH} 4.5 \text { for } \\
40 \text { min }\end{array}$ & (Liu et al., 2017) \\
\hline Alkalimonas amylolytica & H209L, Q226V, P477V & $\begin{array}{l}\text { Increased optimum } \mathrm{pH}(\mathrm{pH} 10.0) \text { with } \\
\text { active } \mathrm{pH} \text { range }(\mathrm{pH} 6.0-12.0)\end{array}$ & (Deng et al., 2014) \\
\hline \multicolumn{4}{|c|}{ Substrate and product specificities } \\
\hline $\begin{array}{l}\text { Talaromyces leycettanus } \\
\text { JCM12802 }\end{array}$ & $\begin{array}{l}\text { CBM20-linker substitution ( } 7 \text { to } 21 \\
\text { residues) }\end{array}$ & $\begin{array}{l}\text { Increased ( }>65.3 \%) \text { substrate } \\
\text { specificities in vitro }\end{array}$ & (Zhang et al., 2017) \\
\hline \multirow[t]{3}{*}{$\begin{array}{l}\text { Saccharomycopsis } \\
\text { fibuligera } \mathrm{R} 64\end{array}$} & Y401W & $\begin{array}{l}\text { Increased }(\approx 10 \%) \text { substrate } \\
\text { specificities in vitro }\end{array}$ & (Amalia et al., 2016) \\
\hline & S383Y, S386W & $\begin{array}{l}\text { Improved }(86.5 \%) \text { substrate affinity at } \\
20 \text { ns in silico }\end{array}$ & (Yusuf et al., 2017) \\
\hline & $\begin{array}{l}\text { S383Y, S386W, N421G, S278N, } \\
\text { A284K, Q384K, K398R, } \\
\text { G400 S401insTDGS }\end{array}$ & $\begin{array}{l}\text { Improved }(29.3 \%) \text { substrate affinity at } \\
100 \mathrm{~ns} \text { in silico }\end{array}$ & $\begin{array}{l}\text { (Baroroh et al., } \\
\text { 2019) }\end{array}$ \\
\hline B. subtilis $\mathrm{CN} 7$ & Y204(F, I), V260(I, L) & $\begin{array}{l}\text { Increased glucose }(\mathrm{G} 1) \text { production than } \\
\text { maltose }(\mathrm{G} 2)\end{array}$ & (Wang et al., 2020) \\
\hline \multirow[t]{2}{*}{ B. stearothermophilus } & G109(N, D, F) & $\begin{array}{l}\text { Increased maltohexaose }(\mathrm{G} 6) \\
\text { production }(36.1,42.4,39.0 \% \\
\text { respectively) }\end{array}$ & (Xie et al., 2020) \\
\hline & W139(A, L, Y) & $\begin{array}{l}\text { Increased maltopentaose (G5) } \\
\text { production }\end{array}$ & (Xie et al., 2019) \\
\hline Rhizopus oryzae & $\mathrm{H} 286(\mathrm{~L}, \mathrm{M})$ & $\begin{array}{l}\text { Increased affinities towards maltotriose } \\
\text { (G3) and soluble starch; increased G2 } \\
\text { production }\end{array}$ & (Li et al., 2018) \\
\hline B. stearothermophilus & $\mathrm{W} 177(\mathrm{~F}, \mathrm{Y}, \mathrm{L}, \mathrm{N}, \mathrm{S})$ & Reduced G3 formation through & (Sun et al., 2016) \\
\hline
\end{tabular}


increased hydrolysis of soluble starch

\begin{tabular}{|c|c|c|c|}
\hline \multirow{2}{*}{\multicolumn{4}{|c|}{ Oxidative stability }} \\
\hline & & & \\
\hline \multirow[t]{2}{*}{ Alkalimonas amylolytica } & M145I-214A-229T-247T-317I & $\begin{array}{l}\text { Improved (5.4-fold) and maintained } \\
91.3 \% \text { activity in } 500 \mathrm{mM} \mathrm{H}_{2} \mathrm{O}_{2} \text { for } 1 \mathrm{~h}\end{array}$ & (Yang et al., 2013a) \\
\hline & Fusion of oligopeptide at N-terminal & $\begin{array}{l}\text { Improved (2.7-fold) and maintained } \\
54 \% \text { activity in } 500 \mathrm{mM} \mathrm{H}_{2} \mathrm{O}_{2} \text { for } 30 \\
\text { min }\end{array}$ & (Yang et al., 2013b) \\
\hline Thermotoga maritima & M55A, (M43A, M44A) & $\begin{array}{l}\text { Maintained } 50 \% \text { and } 39 \% \text { activity in } \\
100 \mathrm{mM} \mathrm{H}_{2} \mathrm{O}_{2} \text {, respectively }\end{array}$ & (Ozturk et al., 2013) \\
\hline Alkalimonas amylolytica & M247L & Improved oxidative resistance $(72 \%)$ & (Yang et al., 2012) \\
\hline Bacillus sp. strain TS-23 & Truncated C-terminal, M231L & $\begin{array}{l}\text { Maintained }>96 \% \text { activity in } 500 \mathrm{mM} \\
\mathrm{H}_{2} \mathrm{O}_{2}\end{array}$ & (Chi et al., 2010) \\
\hline $\begin{array}{l}\text { G. stearothermophilus } \\
\text { US100 }\end{array}$ & $\Delta \mathrm{I} 214-\mathrm{G} 215, \mathrm{M} 197 \mathrm{~A}$ & $\begin{array}{l}\text { Maintained } 70 \% \text { activity in } 1.8 \mathrm{M} \mathrm{H}_{2} \mathrm{O}_{2} \\
\text { for } 60 \text { min }\end{array}$ & $\begin{array}{l}\text { (Khemakhem et al., } \\
\text { 2009) }\end{array}$ \\
\hline
\end{tabular}

